Full length article

\title{
Highly degradable porous melt-derived bioactive glass foam scaffolds for bone regeneration
}

\author{
Amy Nommeots-Nomm ${ }^{\mathrm{a}}$, Sheyda Labbaf ${ }^{\mathrm{b}}$, Aine Devlin ${ }^{\mathrm{c}}$, Naomi Todd ${ }^{\mathrm{c}}$, Hua Geng ${ }^{\mathrm{d}}$, Anu K. Solanki ${ }^{\mathrm{a}}$, \\ Hok Man Tang ${ }^{\mathrm{a}}$, Polytimi Perdika ${ }^{\mathrm{a}}$, Alessandra Pinna ${ }^{\mathrm{a}}$, Fatemeh Ejeian ${ }^{\mathrm{b}}$, Olga Tsigkou ${ }^{\mathrm{d}}$, Peter D. Lee ${ }^{\mathrm{d}}$, \\ Mohammad Hossein Nasr Esfahani ${ }^{\mathrm{e}}$, Christopher A. Mitchell ${ }^{\mathrm{c}}$, Julian R. Jones ${ }^{\mathrm{a}, *}$ \\ a Department of Materials, Imperial College London, South Kensington Campus London, SW7 2AZ, UK \\ ${ }^{\mathrm{b}}$ Biomaterials Research Group, Department of Materials Engineering, Isfahan University of Technology, Isfahan 84156-83111, Iran \\ ${ }^{\mathrm{C}}$ Centre for Molecular Biosciences, University of Ulster at Coleraine, Coleraine BT52 1SA, UK \\ ${ }^{\mathrm{d}}$ School of Materials, University of Manchester, Manchester M13 9PL, UK \\ ${ }^{\mathrm{e}}$ Department of Cellular Biotechnology, Cell Science Research Center, Royan Institute for Biotechnology, ACECR, Isfahan, Iran
}

\section{A R T I C L E I N F O}

Article history:

Received 4 January 2017

Received in revised form 21 April 2017

Accepted 25 April 2017

Available online 27 April 2017

\section{Keywords:}

Bioactive glass

Bioglass

Scaffold

Bone regeneration

Rabbit model

\begin{abstract}
A B S T R A C T
A challenge in using bioactive melt-derived glass in bone regeneration is to produce scaffolds with interconnected pores while maintaining the amorphous nature of the glass and its associated bioactivity. Here we introduce a method for creating porous melt-derived bioactive glass foam scaffolds with low silica content and report in vitro and preliminary in vivo data. The gel-cast foaming process was adapted, employing temperature controlled gelation of gelatin, rather than the in situ acrylic polymerisation used previously. To form a 3D construct from melt derived glasses, particles must be fused via thermal processing, termed sintering. The original Bioglass ${ }^{\circledR} 45 \mathrm{~S} 5$ composition crystallises upon sintering, altering its bioactivity, due to the temperature difference between the glass transition temperature and the crystallisation onset being small. Here, we optimised and compared scaffolds from three glass compositions, ICIE16, PSrBG and 13-93, which were selected due to their widened sintering windows. Amorphous scaffolds with modal pore interconnect diameters between $100-150 \mu \mathrm{m}$ and porosities of $75 \%$ had compressive strengths of $3.4 \pm 0.3 \mathrm{MPa}, 8.4 \pm 0.8 \mathrm{MPa}$ and $15.3 \pm 1.8 \mathrm{MPa}$, for ICIE16, PSrBG and 13-93 respectively. These porosities and compressive strength values are within the range of cancellous bone, and greater than previously reported foamed scaffolds. Dental pulp stem cells attached to the scaffold surfaces during in vitro culture and were viable. In vivo, the scaffolds were found to regenerate bone in a rabbit model according to X-ray micro tomography imaging.
\end{abstract}

\section{Statement of Significance}

This manuscript describes a new method for making scaffolds from bioactive glasses using highly bioactive glass compositions. The glass compositions have lower silica content that those that have been previously made into amorphous scaffolds and they have been designed to have similar network connectivity to that of the original (and commercially used) 45S5 Bioglass. The aim was to match Bioglass' bioactivity.

The scaffolds retain the amorphous nature of bioactive glass while having an open pore structure and compressive strength similar to porous bone (the original 45S5 Bioglass crystallises during sintering, which can cause reduced bioactivity or instability).

The new scaffolds showed unexpectedly rapid bone regeneration in a rabbit model.

(c) 2017 Acta Materialia Inc. Published by Elsevier Ltd. This is an open access article under the CC BY-NC-ND license (http://creativecommons.org/licenses/by-nc-nd/4.0/).

\footnotetext{
* Corresponding author.

E-mail address: julian.r.jones@imperial.ac.uk (J.R. Jones).
}

\section{Introduction}

There is a current need for better bone graft substitutes to regenerate diseased or damaged bone to its original state and function. Bioactive glass scaffolds, with a suitable interconnected 
porous structure similar to that of trabecular bone [1], have the potential to aid the regeneration process by giving cells a temporary template to grow into. Bioactive glasses can form a chemical bond with bone and dissolve over time, provoking bone cell activity. Their dissolution products have been found to up-regulate seven families of genes in osteoblasts [2,3], termed 'osteostimula tion'. $45 \mathrm{~S} 5$ (46.1 mol\% $\mathrm{SiO}_{2}, 24.4 \mathrm{~mol} \% \mathrm{Na}_{2} \mathrm{O}, 26.9 \mathrm{~mol} \% \mathrm{CaO}$ and $2.6 \mathrm{~mol} \% \mathrm{P}_{2} \mathrm{O}_{5}$ ) is the original melt-derived bioactive glass composition [4] and is produced by quenching from a melt and available commercially in a powder form, e.g. as the product NovaBone ${ }^{\circledR}$ (NovaBone Products LLC, Alachua, FL). However, 45S5 cannot be sintered into 3D constructs while maintaining its amorphous glass structure. This is due to the narrow thermal processing window between its glass transition temperature $\left(\mathrm{T}_{\mathrm{g}}\right)$ and its crystallisation onset temperature $\left(\mathrm{T}_{\text {Conset }}\right)$ [5]. To enable sintering of mechanically robust scaffolds, the glass must be reheated to above $T_{g}$ to enable the particles to undergo viscous flow and fuse. However, if the sintering window is too narrow, it is difficult to keep the glass amorphous. The transformation between amorphous and crystalline structure affects bioactivity by altering its dissolution profile [6]. New bioactive glass compositions have recently been designed with an increased sintering window, allowing thermal processing post melt quenching $[7,8]$. An optimum sintering window would allow viscous flow of the particles to form a homogenous surface without crystallisation or macrostructure distortion occurring.

Literature currently presents a variety of methods for producing porous bioactive glass scaffolds, with two processes being predominately used: the foam replica (reticulation) method and robocasting or direct ink writing (extrusion 3D printing). The foam replica method employs a polyurethane foam to act as a sacrificial template to form the scaffold. A glass particle slurry coats the foam template, which is then burnt out using a two-step sintering process creating scaffolds with a porous foam architecture [9]. While, a porous structure is obtained, the main limitation of this processing method is the mechanical properties of the scaffolds produced. Due to the processing method, the struts, which take the mechanical load, can end up being hollow, reducing overall strength of the scaffold $[10,11]$. In contrast, robocasting is a 3D printing technique that prints glass particles dispersed within a polymeric binder. For successful printing, particle size and distribution [12] and the rheological properties of the binder/glass blend are key. The binder should exhibit shear thinning rheology, be able to take high particle loadings and burn out below the $\mathrm{T}_{\mathrm{g}}$ of the glass. Typically, 3D grid-like structures are printed, creating uniform rectangular interconnected porosity in $\mathrm{x}, \mathrm{y}$ and $\mathrm{z}$ directions [12].

Both processes have been used to produced scaffolds from the glass composition 13-93 (54.6 mol\% $\mathrm{SiO}_{2}, 22.4 \mathrm{~mol} \% \mathrm{CaO}, 6 \mathrm{~mol} \%$ $\mathrm{Na}_{2} \mathrm{O}, 1.7 \mathrm{~mol} \% \mathrm{P}_{2} \mathrm{O}_{5}, 7.9 \mathrm{~mol} \% \mathrm{~K}_{2} \mathrm{O}, 7.7$. mol\% MgO). Scaffolds produced by the foam replica method featured porosities of $85 \%$ with interconnects between $100-500 \mu \mathrm{m}$, and compressive strengths of $11 \pm 2 \mathrm{MPa}$ [13]. In contrast, robocast scaffolds had comparable interconnects of $500 \mu \mathrm{m}$ in xy and $100 \mu \mathrm{m}$ in $\mathrm{z}$, at porosities of $60 \%$ and strengths of $136 \pm 22 \mathrm{MPa}$ [14]. Although robocasting can produce scaffolds of much higher mechanical strengths in compression, compared to open cell foams, the strength is due to the grid-like morphology of the scaffolds. As yet, foam-like scaffolds that mimic the structure of porous bone have not been $3 \mathrm{D}$ printed in glass or ceramic. It is not yet known whether the ordered pore channels, made by 3D printing, are favourable for bone ingrowth compared to the more cancellous-like pore foam structures that clinicians are more familiar with.

An alternative method for producing foam scaffolds is through direct foaming of a glass particle slurry with the aid of a surfactant (gel cast foaming) [5]. The surfactant stabilises air bubbles in the slurry and rapid gelation is then required to solidify the slurry so that bubbles can form the pores of the scaffold. It is hypothesised that the advantage of the direct foaming is that the mechanical properties are enhanced compared to foam replicates as the struts will not be hollow. The adapted gel cast foaming process developed herein evolved from work by Wu et al. [5]. Wu et al.'s process used in situ polymerisation of acrylic monomers to form the gel. After a stable foam was formed, the polymer was burned out and the particles sintered together. The scaffolds produced from ICIE16 (49.46 mol\% $\mathrm{SiO}_{2}$, $36.6 \mathrm{~mol} \% \mathrm{CaO}, 6.6 \mathrm{~mol} \% \mathrm{Na}_{2} \mathrm{O}, 1.07 \mathrm{~mol} \% \mathrm{P}_{2} \mathrm{O}_{5}$, $6.6 \mathrm{~mol} \% \mathrm{~K}_{2} \mathrm{O}$ ) glass had porosities of $79 \%$, with modal pore diameters of $379 \mu \mathrm{m}$ and compressive strength of $1.9 \mathrm{MPa}$. These values were a factor of 10 lower than those reported by Fu et al. [13] of foam replica scaffolds manufactured from 13-93.

The limitation of the $\mathrm{Wu}$ et al. process was that the gelation reaction was so rapid that the window to transfer the foam into moulds prior to gelation was approximately $2 \mathrm{~s}$. Pouring too early resulted in a collapse of the foam and too late would not produce any scaffolds; this made up-scaling difficult. Another problem was the formation of potassium sodium sulphate on the glass surface during sintering. This was due to the ammonium persulfate initiator, used for the free radical polymerisation of the acrylic, reacting with sodium and potassium ions that leached from the glass particles. Although the sulphate is thought to be non-toxic, it changed the topography of the surface and hampered sintering between the particles, reducing compressive strength. A method that widens the gelation window without potassium sodium sulphate formation is needed.

13-93 is the most common bioactive glass used for 3D scaffolds, due to its thermal processing capability of good viscous flow forming continuous material without crystallisation [8]. However, it may have lower bioactivity than 45S5 Bioglass due to the higher silica content forming a highly connected network that is more resistant to dissolution. Hill and Brauer [15] proposed a method of predicting bioactivity of bioactive glasses based on their nominal composition, known as the modified network connectivity (Eq. (1)). This calculation uses the glass composition (in mol\%), where $\mathrm{M}_{\mathrm{f}}$ is the molar fraction of the network forming oxide, e.g. Si, and $M_{2}^{1} O$ and $M^{I I} O$ are the respective molar fractions of the mono and divalent modifier oxides within the glass. This calculation assumes that phosphate forms its own orthophosphate network, charged balanced by divalent cations.

$\mathrm{NC}^{\prime}=\frac{4\left(\mathrm{M}_{f}\right)-2\left(M_{2}^{1} O+M^{I I} O\right)+6\left(M_{P_{2} O_{5}}\right)}{\mathrm{M}_{f}}$

The original 45S5 Bioglass has an NC' value of 2.11. As 45S5 has been used clinically with excellent results, the aim here was to design glass scaffolds that remain amorphous but have a NC' value as close to 2.11 as possible. The relationship of network connectivity and bioactivity is limited by various factors: for example, it assumes that the glass is homogeneous with a uniform distribution of ions throughout the system. It also assumes that once a bridging oxygen bond is broken and replaced with a non-bridging oxygen that the initial bond disappears, whereas in reality it depends on the replacing ion and its size and charge. Thirdly it requires the user to define what role a particular atom will play within the network, which can be a challenge. For example, magnesium's role within the glass network is currently debated within the literature. Watts et al. [16] showed that in their particular compositional series magnesium can enter the network as both a former $\left(\mathrm{MgO}_{4}\right)$ and a modifier $\left(\mathrm{Mg}^{2+}\right)$, with $\sim 14 \%$ of the total magnesium acting as a network former [16].

Here, the aim was to develop a modified thermal gelation method for the gel-cast foaming process, combined with glasses of network connectivity similar to Bioglass, without forming surface crystals as a by-product of the gelation. Three silicate glass compositions ICIE16, PSrBG, and 13-93 were compared with vary- 
ing $\mathrm{NC}^{\prime}$ values of $2.13,2.58,2.31$ respectively (Table 1 ). The network connectivity values suggest that ICIE16 should be the most bioactive as its network connectivity is closest to that of 45S5 (2.11), followed by PSrBG and 13-93. A second objective was to investigate biological response to the new scaffolds in vitro and in vivo in a critical size rabbit lateral femoral condyle model.

\section{Materials and methods}

\subsection{Glass synthesis}

All reagents were purchased from Sigma Aldrich UK at $>96 \%$ purity, unless otherwise stated. Three glasses ICIE16, PSrBG and 13-93 (Table 1) were produced using high purity silica $\left(\mathrm{SiO}_{2}\right)$ (Prince minerals, Stoke-on-Trent), phosphorous pentoxide $\left(\mathrm{P}_{2} \mathrm{O}_{5}\right)$, magnesium oxides $(\mathrm{MgO})$ and the carbonate equivalent of the modifying oxides. They were mixed prior to melting for at least $8 \mathrm{~h}$ (Wheaton mini roller, UK), then melted at $1400^{\circ} \mathrm{C}$ for $1.5 \mathrm{~h}$, in a Pt-5\%Au crucible. The melt was then quenched into deionised water, the frit was collected and dried at $100{ }^{\circ} \mathrm{C}$. Frit was then ball milled at $500 \mathrm{rpm}$ for $6 \mathrm{~min}$ (Fritsch Premium Line 7 ball mill) and sieved (Russell Finex compact sieve shaker with ultrasonic deblinder) to yield particles with diameters less than $32 \mu \mathrm{m}$.

The glass composition was checked using X-ray Fluorescence (XRF) and by Inductive coupled plasma optical emission spectroscopy (ICP-OES) analysis (Thermo iCAP, Thermo scientific) following lithium metaborate acid digestion. X-ray fluorescence (XRF) was completed both air and helium using a PANalytical Epsilon $3^{\mathrm{XLE}}$ at $30 \mathrm{kV}$ and $0.250 \mathrm{~mA}$ on powders after they were ball milled and sieved to less than $32 \mu \mathrm{m}$. For acid digestion, $100 \mathrm{mg}$ of glass and $400 \mathrm{mg}$ lithium metaborate were mixed and added to a Pt-5\%Au crucible, the mixture was then heated to $1200{ }^{\circ} \mathrm{C}$ for $30 \mathrm{~min}$. The glass was then dissolved under sonication in a known volume of $2 \mathrm{~mol}$ nitric acid (Analytical grade, Fisher UK, CAS 769737-2) and then analysed via ICP-OES. Compositional error was less than $1 \mathrm{~mol} \%$ for each element.

\subsection{Particle size analysis}

Particle size was measured using a Malvern Mastersizer 2000 (Malvern Instruments Ltd. UK). To form stable suspensions suitable for measurement, glass powders were dispersed in water using a sonicator, and ethylene glycol was added to aid dispersion. Refractive index values used were glass: 1.54 , water: 1.33 , ethylene glycol: 1.44 .

\subsection{Gel cast foaming of scaffolds}

Different ratios of type A porcine gelatin (CAS 9000-70-8) were dissolved into $20 \mathrm{ml}$ of deionised water at $25^{\circ} \mathrm{C}$. Glass powder was then added with Triton X100 surfactant. The solution was foamed for 2 min (Kenwood hand mixer), then placed in an ice bath for 8 min until solidified. Samples were then placed in a $-20^{\circ} \mathrm{C}$ freezer for $20 \mathrm{~min}$ followed by $2 \mathrm{~h}$ in a $-80^{\circ} \mathrm{C}$ freezer. On removal from the freezer, the scaffolds were freeze dried (CoolSafe 100-4 freeze-drier fitted to a Vacuubrand RZ6 vacuum pump operating at $-110^{\circ} \mathrm{C}$ with an ultimate total vacuum of $1 \times 10^{-2}$ mbar) for 2 days until dry. Prior to sintering, scaffolds were cut with a scalpel blade to shape. Samples were then sintered in a two stage process, with both the temperature and time used being dependent upon glass composition, all sintering processes were conducted at a heating rate of $3{ }^{\circ} \mathrm{C} /$ minute. The values for each variable were investigated and reported within the results section.

\subsection{Samples for in vitro and in vivo studies}

Scaffolds of ICIE16 (in vitro and in vivo) and PSrBG (in vivo only) were produced using the previously stated methodology. The surfactant concentration and thermal processing regimes were selected to obtain similar interconnect pore diameters. ICIE16 scaffolds were made using $0.3 \mathrm{ml}$ of surfactant addition, and sintered using a two-step profile, with dwells at $500{ }^{\circ} \mathrm{C}$ for $1 \mathrm{~h}$ and at $690{ }^{\circ} \mathrm{C}$ for $1.5 \mathrm{~h}$. PSrBG scaffolds were formed using $0.4 \mathrm{ml}$ of surfactant and sintered again using a two-step profile, with dwells at $500{ }^{\circ} \mathrm{C}$ for $1 \mathrm{~h}$ and at $700{ }^{\circ} \mathrm{C}$ for $5 \mathrm{~h}$. Both ICIE16 and PSrBG sintered profiles were conducted at a rate of $3{ }^{\circ} \mathrm{C} / \mathrm{min}$. Scaffolds used for the in vivo study are summarised in Table 2.

\subsection{Nitrogen sorption (BET)}

Samples were degassed for $24 \mathrm{~h}$ at 200C, nitrogen sorption run on a Quantachrome (Hook, UK) ASiQWininstrument, with surface area calculated using the multipoint BET method [17].

\subsection{Differential scanning calorimetry}

A $50 \mathrm{mg}$ sample of Type A porcine gelatin was placed in a platinum crucible. Analysis was completed in continuously flowing air up to $1200{ }^{\circ} \mathrm{C}$ at a heating rate of $10^{\circ} \mathrm{C} \mathrm{min}-1$ using a NETZSCH STA 449C Dual Thermogravimetric Analysis-Differential Scanning Calorimeter. The reference sample used was alumina. Calibration scans were run of both empty crucibles and just the reference sample to reduce error.

\subsection{Mercury porosimetry}

Mercury Porosimetry was carried out using a Quantachrome Poremaster 33 (Quantachrome UK, Hook, UK). Sample volumes were recorded and their masses inputted into the software, cylinders of approximately $1 \mathrm{~cm}^{3}$ were used and five repeats were done of each sample set tested. The samples were left under vacuum for 30 min prior to infiltration, and then filled with mercury under nitrogen gas as a function of pressure. Raw data was analysed using PoreMaster for windows 8.1 software.

\subsection{Compression testing}

Cube shaped scaffolds with parallel faces and dimensions of $6 \times 6 \times 6 \mathrm{~mm}$ were tested under compression using a $10 \mathrm{kN}$ load

Table 1

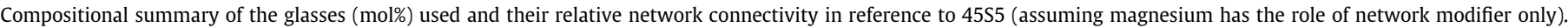

\begin{tabular}{|c|c|c|c|c|c|c|c|c|c|c|c|}
\hline Oxide: mol\% & $\mathrm{SiO}_{2}$ & $\mathrm{CaO}$ & $\mathrm{Na}_{2} \mathrm{O}$ & $\mathrm{P}_{2} \mathrm{O}_{5}$ & $\mathrm{~K}_{2} \mathrm{O}$ & $\mathrm{MgO}$ & $\mathrm{SrO}$ & $\begin{array}{l}\text { Network } \\
\text { formers }\end{array}$ & $\begin{array}{l}\text { Network } \\
\text { modifiers }\end{array}$ & $\begin{array}{l}\text { Possible network } \\
\text { intermediates }\end{array}$ & $\begin{array}{l}\text { Modified network } \\
\text { connectivity }\end{array}$ \\
\hline $45 S 5$ & 46.13 & 26.91 & 24.35 & 2.6 & & & & 48.73 & 51.26 & & 2.11 \\
\hline ICIE16 & 49.46 & 36.6 & 6.6 & 1.07 & 6.6 & & & 50.53 & 49.47 & & 2.13 \\
\hline $13-93$ & 54.6 & 22.4 & 6 & 1.7 & 7.9 & 7.7 & & 56.30 & 43.70 & 7.70 & 2.58 \\
\hline PSrBG & 44.5 & 17.8 & 4 & 4.5 & 4 & 7.5 & 17.8 & 49.0 & 51.0 & 7.50 & 2.31 \\
\hline
\end{tabular}


Table 2

Summary of in vivo samples.

\begin{tabular}{|c|c|c|c|c|c|}
\hline Glass & Porosity/\% & Modal interconnect diameter $/ \mu \mathrm{m}$ & Diameter/mm & Thickness/mm & Surface Area $/ \mathrm{m}^{2} \mathrm{~g}^{-1}$ \\
\hline PSrBG & $88.82 \pm 1.83$ & $109.2 \pm 4.5$ & $6.54 \pm 0.09$ & $1.53 \pm 0.06$ & $2.59 \pm 0.89$ \\
\hline ICIE16 & $85.76 \pm 2.96$ & $111.3 \pm 12.2$ & $6.44 \pm 0.20$ & $1.49 \pm 0.09$ & $5.60 \pm 0.69$ \\
\hline
\end{tabular}

cell at strain rate of $1 \mathrm{~mm} . \mathrm{min}^{-1}$ using a Zwick/Roell z2.5 machine fitted. A total of 10 scaffolds of each glass composition were tested with comparable porosities between $73-77 \%$, the results shown are the average values and the error bars represent the standard deviations.

\subsection{Simulated body fluid testing}

Scaffolds of each glass composition, with modal interconnect sizes between 100-150 $\mu \mathrm{m}$, were produced and immersed in Simulated Body Fluid (SBF) [18] using approved conditions, i.e. at a ratio of $150 \mathrm{mg}$ to $100 \mathrm{ml}$ of solution [19] with the samples sealed and placed in an orbital incubator (Newbrunswick Scientific - Classic Series C24) at $120 \mathrm{rpm}$ at $37^{\circ} \mathrm{C}$. At each time point $(1,2,4,8,24$, $48,72,168,336,504$ and $672 \mathrm{~h} ; \mathrm{n}=3$ ), the $\mathrm{pH}$ was measured, a $1 \mathrm{ml}$ sample of SBF taken and subsequently replaced (with stock SBF solution) to keep the sample/volume ratio constant. At each time point, scaffolds were rinsed in acetone and dried for further analysis via SEM, XRD and FTIR. Samples for ICP-OES were diluted with $9 \mathrm{ml}$ of $2 \mathrm{M}$ nitric acid. They were analysed for each element present within the glass, if concentration levels were outside of the $0-40 \mu \mathrm{g} \mathrm{ml}^{-1}$ then a further dilution was conducted at a ratio of 1:9 with $2 \mathrm{M}$ nitric acid. The results shown are the averages of each time point and the error bars represent the standard deviations.

\subsection{0. $X$-ray diffraction $(X R D)$}

Glass scaffolds were ground into a fine powder prior to analysis. The spectra were collected using a Bruker D2 PHASER desktop Xray diffractometer with a step size of $0.0332^{\circ}, 10$ s per step, measuring between 5 and 80 degrees $2 \theta$. The radiation source was $\mathrm{Ni}$ filtered $\mathrm{CuK} \alpha$.

\subsection{Fourier transform infrared spectroscopy (FTIR)}

All samples were ground into a fine powder prior to testing and spectra were collected between $450-4000 \mathrm{~cm}^{-1}$ at a resolution of $2 \mathrm{~cm}^{-1}$ and averaged over 64 scans. The data was collected using a Scientific Nicolet iS10 Spectrometer operating in attenuated reflectance (ATR) mode.

\subsection{Scanning electron microscopy (SEM)}

Low magnification images of the scaffolds were collected using the JEOL JSM 5610 LV with a working distance of $10-12 \mathrm{~mm}$. Samples were mounted onto conductive stubs using carbon tape and sputter coated in gold using an Emitech $\mathrm{K} 550$ for two minutes at $25 \mathrm{~mA}$. Due to the porous nature of the scaffolds one side was painted with silver to increase the conductivity of the samples. Images were taken using a voltage of $5 \mathrm{kV}$ to reduce charging of the samples. High magnification images were collected using a Field Emission Gun (FEG) SEM (LEO 5610), samples were sputter coated in chromium for two minutes at $30 \mathrm{~mA}$. A voltage of $5 \mathrm{kV}$ was used with a working distance of $5-10 \mathrm{~mm}$.

\subsection{In vitro cell culture}

\subsubsection{Dental pulp stem cell isolation}

Intact human impacted third molars with immature roots were collected from healthy patients ( 3 donors aged $15-20$ years) in the Dental Clinics at the Islamic Azad University of Khorasgan under approved guidelines by the Ethical committee of Royan institute (EC/91/1148). All experiments were conducted after patients had signed informed consent forms. Dental stem cells were isolated as previously described [20]: the apical papillae of teeth were cut out with a sterile blade in cold phosphate buffered saline (PBS), and then extracted molars were sectioned at cemento-enamel junction (CEJ) to remove pulp tissue; isolated pulp was washed three times with PBS, minced and digested in a solution of $4 \mathrm{mg} \mathrm{ml}^{-1}$ collagenase type I (Gibco,UK) for approximately $60 \mathrm{~min}$ at $37^{\circ} \mathrm{C}$. Single-cell suspensions were prepared by passing the cells through a $70 \mu \mathrm{m}$ strainer and were initially grown in Minimum Essential Medium $\alpha$-Modification ( $\alpha$-MEM, Sigma, UK) supplemented with $15 \%$ fetal bovine serum (FBS, Gibco,UK), 1\% L-glutamine (Gibco, $\mathrm{UK}), \quad 100 \mathrm{U} \mathrm{ml}^{-1}$ penicillin and $100 \mathrm{mg} \mathrm{ml}^{-1}$ streptomycin at $37{ }^{\circ} \mathrm{C}, 5 \% \mathrm{CO}_{2}$ and were allowed to reach $85 \%$ confluency. The explanted dental pulp stem cells (DPSCs) were then subcultured in Dulbecco's Modified Eagle's medium (DMEM) supplemented with $10 \%$ FBS, $1 \%$ L-glutamine (Gibco, UK), $100 \mathrm{U} \mathrm{ml}^{-1}$ penicillin and $100 \mathrm{mg} \mathrm{ml}^{-1}$ streptomycin, referred to from further on as complete medium. All experiments were carried out by using DPSCs from the same donor at passage 3 .

\subsubsection{Cell culture on scaffolds}

The ICIE16 scaffolds were cut into $3 \times 3 \times 3 \mathrm{~mm}$ cubes and sterilized in dry heat $\left(200^{\circ} \mathrm{C}\right.$ for $2 \mathrm{~h}$ ) prior to use. Preconditioning of scaffolds was performed by immersion in serum-free DMEM ( $3 \mathrm{mg}$ glass per ml DMEM), supplemented with $100 \mathrm{U} \mathrm{ml}^{-1}$ penicillin and $100 \mathrm{mg} \mathrm{ml}^{-1}$ streptomycin, at $37^{\circ} \mathrm{C}$ for $48 \mathrm{~h}$. Following preconditioning, the culture media were collected and filtered through $0.2 \mu \mathrm{m}$ syringe filters to be analysed by ICP-OES. Following preconditioning, scaffolds were washed with PBS and transferred to a 24-well plate. Cell seeding was performed by addition of concentrated cell suspension in a drop-wise manner to ensure cell loading directly onto the scaffolds. Specifically, $100 \mu$ of complete medium containing 50,000 cells was pipetted directly onto the scaffolds surface and incubated at $37^{\circ} \mathrm{C}, 5 \% \mathrm{CO}_{2}$ for $20 \mathrm{~min}$. The wells were then filled with $1 \mathrm{ml}$ complete media and cultured for $1,3,5$ and 7 days, under static conditions at $37{ }^{\circ} \mathrm{C}, 5 \% \mathrm{CO}_{2}$, humidified atmosphere. Medium was collected after each time point for ionic concentration analysis using ICP-OES. The preconditioned scaffolds were also used for analysis by XRD (protocol above).

\subsubsection{Cell attachment}

Following $24 \mathrm{~h}$ of cell culture, as described above, cell-scaffold constructs were fixed using $2.5 \%$ glutaraldehyde (Sigma, UK) in PBS for 40 min at $4{ }^{\circ} \mathrm{C}$, washed with PBS, dehydrated through a series of increasing concentrations of ethanol $(0,25,50,75$ and $100 \%)$ and dried using hexamethyldisilazane (HMDS, Sigma) after which they were sputter coated with gold and viewed using a SEM (SEM, Philips XL30) using an accelerating voltage of $5 \mathrm{kV}$. 


\subsubsection{Cell viability and growth}

DPSC metabolic activity over time following culture on scaffolds was assessed using MTS and Alamar blue. Since both assays are colorimetric, phenol red free DMEM was used. CellTiter $96{ }^{\circledR}$ Aqueous One Solution Cell Proliferation Assay (Promega, UK) was used following the manufacturer's instructions. At each time point, $250 \mu \mathrm{l}$ of MTS solution was added to each 24-well plate and incubated for $3 \mathrm{~h}$ at $37^{\circ} \mathrm{C}$. Following incubation, $100 \mu \mathrm{l}$ were transferred to a 96-well plate and the absorbance was measured at $450 \mathrm{~nm}$ using a microplate reader. Alamar Blue ${ }^{\circledR}$ (Invitrogen, UK) was also used to measure cell metabolic activity. In this assay fluorescence intensity is proportional to the number of living cells and corresponds to metabolic activity of the cell population. At each time point, media was removed and $500 \mu \mathrm{l}$ of Alamar blue solution (1:10 Alamar blue reagent: culture medium) was added to each well and incubated for $2 \mathrm{~h}$. Fluorescence was measured on a fluorescence plate reader at $570 \mathrm{~nm}$. The data are expressed as the mean values and standard deviation (SD) of two individual experiments each performed in triplicate. Differences between groups were determined by an Independent T-test with values of $\mathrm{p}<0.05$ considered significant.

\subsection{Statistical analysis}

All characterisation in vitro experiments were carried out in triplicate, from these the averages and standard deviations were calculated. Within this work the mean values are shown and the standard deviations are presented as error bars.

\subsection{In vivo study}

All animal procedures were approved and conducted in accordance with institutional (University of Ulster) animal care committee and National (UK Home Office) guidelines. A total of 4 female New Zealand half-lop rabbits $(2.1-2.8 \mathrm{~kg})$ were used in this study. General anaesthesia was induced by subcutaneous injection of ketaset and xylapam (in sterile saline), with palliative pain relief ensured by subcutaneous injection of Metacam. Rabbits were intubated and an appropriately plane of anaesthesia was maintained by inhalation of a Fluothane/air mixture.

The surgical site was initially prepared by mechanical clipping of fur, application of a depilatory cream and 3 successive washes with chlorhexidine followed by isopropanol. The rabbits were then placed on their sides and a $5 \mathrm{~cm}$ incision over the lateral aspect of the knee joint was made with a scalpel. The muscle tissue was blunt dissected, retracted from the underlying bone and connective tissue overlying the lateral aspect of the femoral condyle was cleared. A critical-sized $6.5 \mathrm{~mm}$ circular defect was drilled in the femoral condyle down to the level of the marrow cavity (with liberal application of sterile saline to prevent heat-induced osteonecrosis) and bleeding minimised by application of pressure. The pre-sterilized ICIE16 (3 implants) or PSrBG scaffolds ( 3 implants) were then press fitted into the lesion until they were level with the edge of the remaining bony tissue. Muscle tissue was closed with 6:0 suture (Ethilon) and the skin was closed with 4:0 suture. After successful implantation on one leg, the procedure was performed on the contra-lateral leg. Two sites in separate rabbits contained no implant (defect-only) and served as controls.

After surgery, animals received prophylactic topical antibiotics on the surgical site as well as 5 days of oral antibiotics. Pain relief was also administered for 3 days' post-surgery in the form of oral Metacam. At either 7 (one rabbit) or 12 weeks post-implantation (2 rabbits), animals were euthanised and the femur/scaffold samples were removed for subsequent X-ray micro tomography $(\mu \mathrm{CT})$ examination.
The femurs head (scaffolds were included) were scanned using a laboratory based $\mu \mathrm{CT}$ system (nano-focus, Phoenix|X-ray General Electric Company, Measurement and Control). The energy of the scanner used was $70 \mathrm{kV}$ with $140 \mathrm{~mA}$ current. Each scan yielded projection data set of 1000 2D projections, the size of the reconstructed images was $1989 \times 1989 \times 1000$ voxels with an isotropic voxel size of $9.5 \mu \mathrm{m}$. The 3D images of the femur/scaffold sample were obtained using Avizo Image processing software (Visualisation Sciences Group, Merignac Cedex, France). Three dimensional morphology analysis was performed on newly formed bone in manually selected volume of interest (VOI); the total amount of newly formed bone was quantified as previously detailed [21].

\section{Results and discussion}

\subsection{Adapted gel-casting process optimisation}

The initial aim was to determine whether foam scaffolds could be produced from low silica glasses using gelatin as the gelation agent in the gel-cast foaming process. One glass composition (PSrBG) was used as proof of principle by studying the gelatin to water ratio and the glass loading. Then, the amount of surfactant required to form scaffold morphologies suitable for bone ingrowth [22] and the sintering temperature were then optimised specifically for each glass composition.

\subsubsection{Gelatin concentration for gelation}

Gelatin is a natural polymer with viscosity dependent upon the ambient temperature under certain conditions it can act as a binder for particles to form mechanically stable green bodies
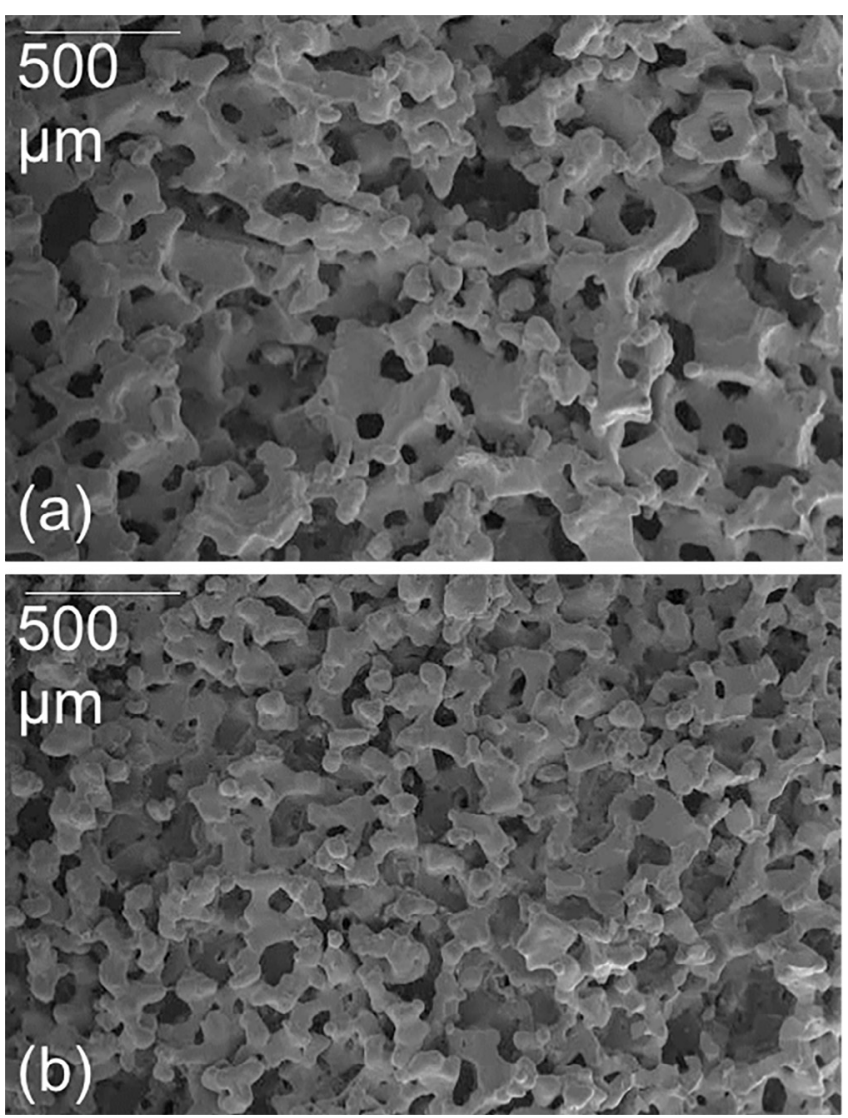

Fig. 1. SEM images of PSrBG scaffolds foamed with $0.2 \mathrm{ml}$ surfactant and (a) $1 \mathrm{~g}$ gelatin; (b) $2 \mathrm{~g}$ of gelatin, sintered at $690^{\circ} \mathrm{C}$ for $3 \mathrm{~h}$. 
[23-25]. The effect of gelatin concentration on the ability to produce a foamed structure, of PSrBG, was investigated using $0.2 \mathrm{ml}$ of surfactant and scaffolds were sintered for $3 \mathrm{~h}$ at $690^{\circ} \mathrm{C}$.

Gelatin content was studied at $0.5 \mathrm{~g}, 1 \mathrm{~g}$ and $2 \mathrm{~g}$ dissolved in $20 \mathrm{ml}$ of deionised water with $0.2 \mathrm{ml}$ of surfactant addition. At $0.5 \mathrm{~g}$, the gelatin concentration was insufficient to gel the slurry, resulting in collapse of the foam once agitation was stopped. $1 \mathrm{~g}$ of gelatin produced a successful foam (foam volume of $100 \mathrm{ml}$ from $\sim 40 \mathrm{ml}$ starting slurry) with open pores (Fig. 1a). However, when the amount of gelatin was increased to $2 \mathrm{~g}$, the viscosity was too high, and a reduction of foam volume to $60-70 \mathrm{ml}$ was seen (Fig. 1b) and the pore network became heterogeneous with pores partially collapsed in some areas. Consequently $1 \mathrm{~g}$ of gelatin in $20 \mathrm{ml}$ of deionised water was used in subsequent experiments.

\subsubsection{Glass concentration in the slurry}

During sintering, the polymeric binder, in this case gelatin, was burnt away leaving the particles supporting one another in the green body. Once the temperature was raised above $T_{g}$, the previously discrete particles fused through viscous flow, forming continuous surfaces. If the glass loading was sufficient, the foam structure was maintained, forming scaffolds which resemble the green body's original morphology. If there was insufficient packing of the particles within the green body, slumping of the structure occurred when the gelatin was burned away, or the foam collapsed under its weight. The effect of glass loading was investigated for loads of between $10-30 \mathrm{~g}$ of glass in $20 \mathrm{ml}$ of water using $0.2 \mathrm{ml}$ of Triton X-100. A loading of $25 \mathrm{~g}$ of glass was found to be optimal.

\subsubsection{Surfactant concentration for the foaming of the slurry}

For all glass compositions, the amount of Triton X-100 surfactant added varied between $0.2-0.6 \mathrm{ml}$ at a set glass: gelatin: water ratio of 25:1:20. Fig. 2a shows SEM images of all three glass compositions at surfactant contents of between $0.2-0.6 \mathrm{ml}$. At low concentrations of surfactant $(0.2 \mathrm{ml})$, the scaffolds formed had limited porosity, with heterogeneous pore morphologies deemed unsuitable for bone regeneration. Increasing the concentration of the surfactant to $0.3 \mathrm{ml}$ and $0.4 \mathrm{ml}$ improved the homogeneity and sphericity of the pores. At 0.5 and $0.6 \mathrm{ml}$ surfactant, the pore diameters continued to increase and started to become irregular in shape. Fig. 2b shows pore interconnect diameter of ICIE16 measured via mercury porosimetry. Interestingly, above surfactant concentrations of $0.2 \mathrm{ml}$, the diameter of the interconnects formed between pores remained at $\sim 100 \mu \mathrm{m}$ which is considered to be suitable for tissue ingrowth [26]. This suggests that the formation of the interconnects was due to rupture of pores during gelation, which was dependent upon the gelatin properties during freezing, not the concentration of surfactant within the system. The porosimetry results corroborated SEM images, from the SEM and mercury results it was deemed that $0.3 \mathrm{ml}$ of surfactant produced them most suitable foams for the ICIE16 composition. Fig. 2c shows the variation in compressive strength of the ICIE16 scaffolds with their corresponding porosities. As expected, the increase in surfactant concentration increased the porosity of the scaffolds resulting in reduced compressive strengths [26]. For both 13-93 and PSrBG compositions, the surfactant concentration had to be increased to $0.4 \mathrm{ml}$ in order to produce foam volumes of $\sim 120 \mathrm{ml}$ that produced scaffolds with similar pore structures and interconnect sizes to those of the ICIE16 composition. (a)

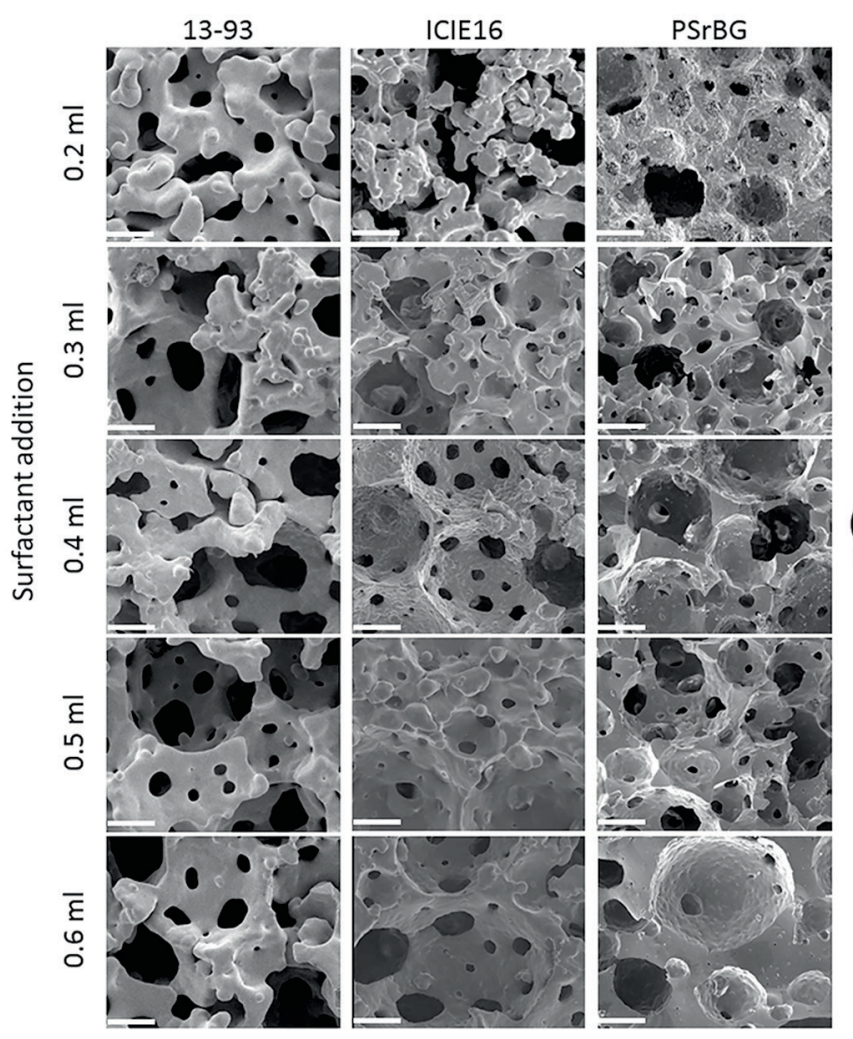

(b)

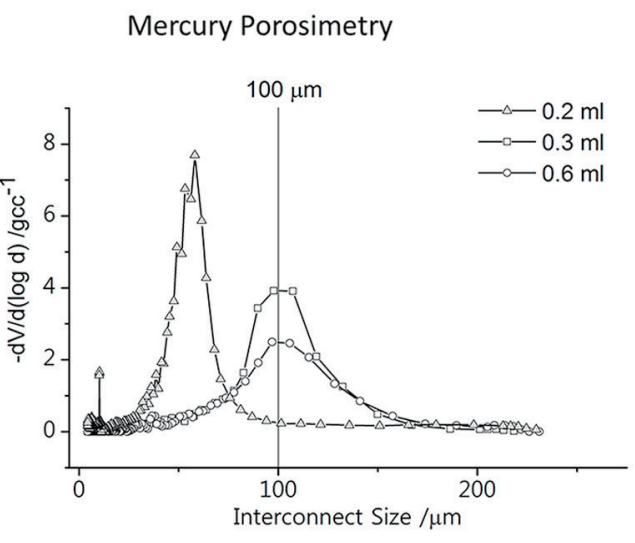

(c)

Compression Testing

Scaffold porosity: $53 \% \quad 71 \% \quad 66 \% \quad 74 \% \quad 67 \% \quad 79 \%$

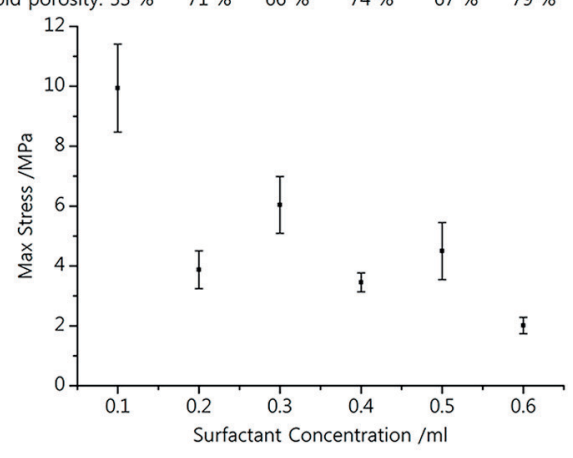

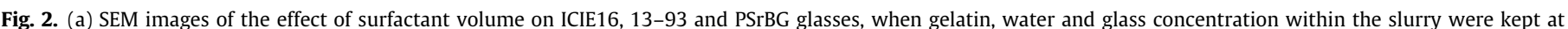

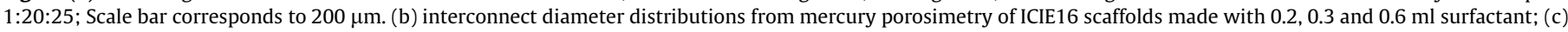

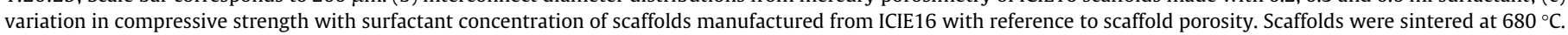




\subsubsection{Sintering regime}

The gel casting method allows scaffolds to be cast and cut into any required shape. If the sintering profile and particle loading are optimised, the scaffolds have the same morphology pre and post sinter. However, if during sintering the viscous flow was too great it produced distortion within the scaffolds, reducing the pore and interconnect size. The aim was to achieve mechanically robust open pored scaffolds which remained amorphous post sintering.

Thermal Gravitation Analysis (TGA) showed that gelatin burned out of the scaffolds below $500{ }^{\circ} \mathrm{C}$ (Fig. 3a). Therefore, a two stage sintering process was adopted, with a dwell of $1 \mathrm{~h}$ at $500^{\circ} \mathrm{C}$, for gelatin removal, and a secondary dwell, which is composition dependent, to sinter the particles.

ICIE16 sintering optimisation is described by Fig. 3. Initially, the sintering temperature (second dwell period) was investigated. Four temperatures $\left(680^{\circ} \mathrm{C}, 690^{\circ} \mathrm{C}, 700^{\circ} \mathrm{C}\right.$ and $\left.710^{\circ} \mathrm{C}\right)$, with $1 \mathrm{~h}$ dwell periods (Fig. $3 \mathrm{c}-\mathrm{f}$ ), were compared via SEM. At $680^{\circ} \mathrm{C}$ and $690{ }^{\circ} \mathrm{C}$, limited viscous flow occurred, with shapes of the particles visible, indicating incomplete sintering (Fig. 3c, d). At $700{ }^{\circ} \mathrm{C}$ and $710{ }^{\circ} \mathrm{C}$ the glass had flowed to form continuous struts (Fig. 3e, f), however the pore shapes and interconnects had started to reduce and change morphology due to the amount of flow which had occurred. Therefore, dwell time at $690^{\circ} \mathrm{C}$ (Fig. 3b) was increased from 1 to $1.5 \mathrm{~h}$, which improved sintering, creating smooth strut morphologies, keeping the scaffold foamed shape, while maintaining the glasses amorphous structure. When the dwell temperature was increased to $2 \mathrm{~h}$, small crystallisation peaks occurred within the XRD patterns and pits formed on the surface of the scaffold (Fig. 3e-f). Sintering was continued at $690{ }^{\circ} \mathrm{C}$ for $5 \mathrm{~h}$ to determine the crystalline phase formed and $\mathrm{Na}_{4.24} \mathrm{Ca}_{3.8}\left(\mathrm{Si}_{6} \mathrm{O}_{18}\right)$ and $\mathrm{Ca}_{2} \mathrm{Si}_{4} \mathrm{Ca}_{3}\left(\mathrm{PO}_{4}\right)_{2}$ were identified (reference codes 01-078-1650 and 00-049-1674 respectively). The diffraction peaks for $\mathrm{Na}_{4.24} \mathrm{Ca}_{3.8}\left(\mathrm{Si}_{6} \mathrm{O}_{18}\right)$ are at $32.5,33$ and $41{ }^{\circ} 2 \theta$, matched the peaks seen at $2 \mathrm{~h}$, suggesting that this phase formed first, and then after an extended time at temperature $\mathrm{Ca}_{2} \mathrm{Si}_{4} \mathrm{Ca}_{3}\left(\mathrm{PO}_{4}\right)_{2}$ formed.
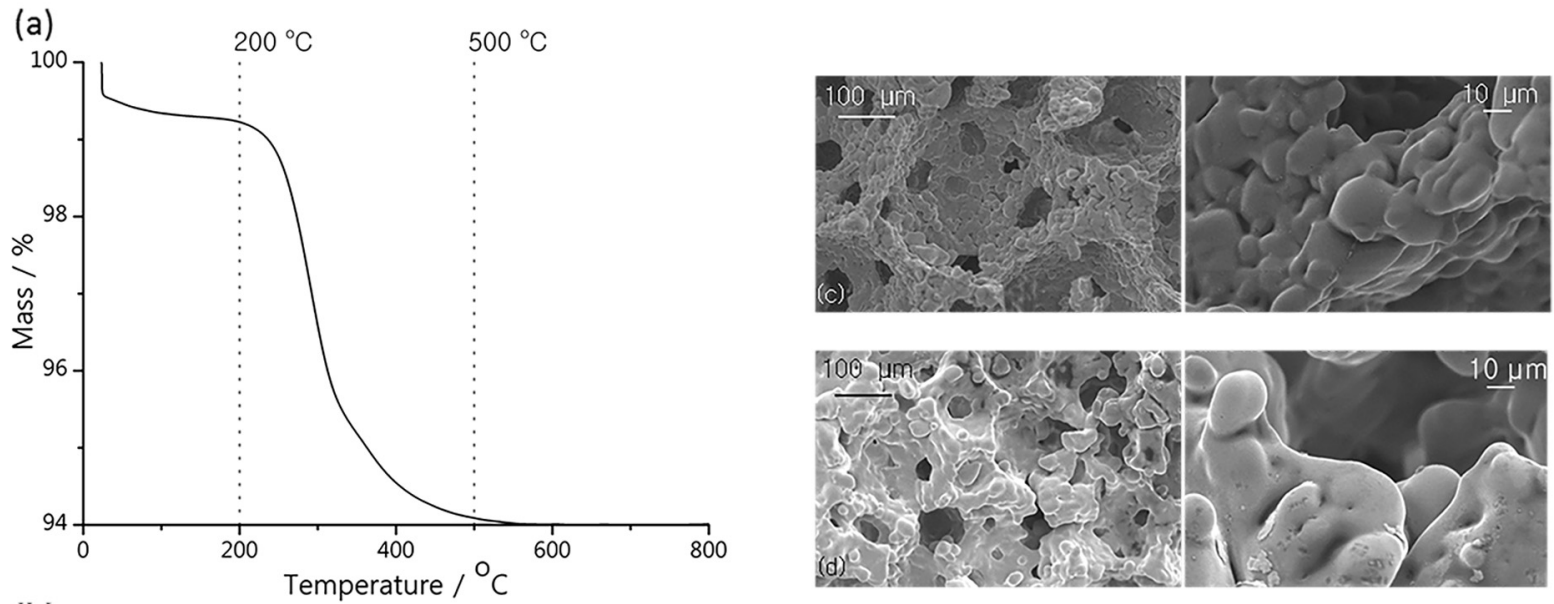

(b)
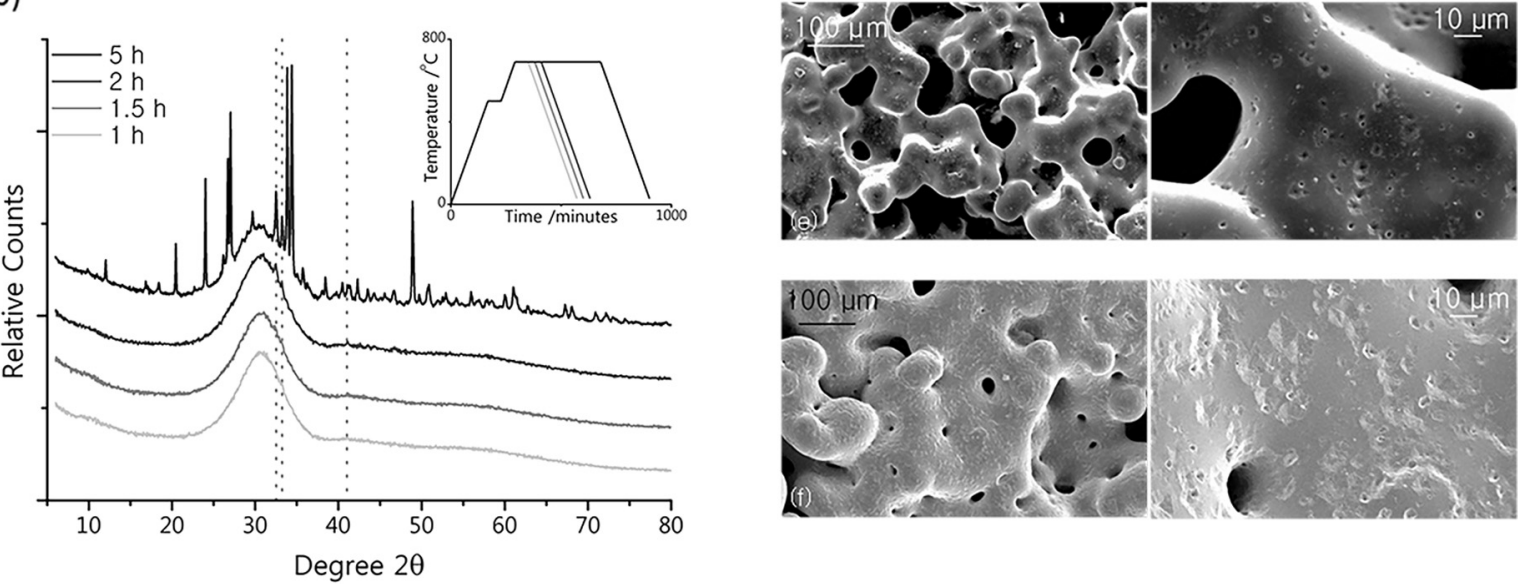

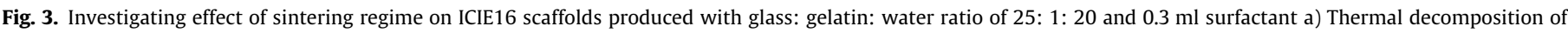

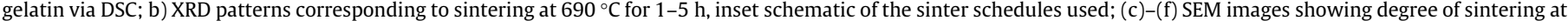
different sintering temperatures with $1 \mathrm{~h}$ dwell: (c) $680^{\circ} \mathrm{C}$; (d) $690^{\circ} \mathrm{C}$; (e) $700{ }^{\circ} \mathrm{C}$; and (f) $710^{\circ} \mathrm{C}$.

Table 3

Summary of processing protocols for the adapted gel-casting process for ICIE16, 13-93 and PSrBG compositions, and the consequent scaffolds properties.

\begin{tabular}{|c|c|c|c|c|c|c|}
\hline Glass & $\mathrm{D}_{10} / \mathrm{D}_{50} / \mathrm{D}_{90} / \mu \mathrm{m}$ & Slurry composition vol\% Water/Gelatin/Glass/Surfactant & Sintering profile & $\mathrm{D}_{\text {mode }} / \mu \mathrm{m}$ & $\% \mathrm{P} / \%$ & $\sigma_{\max } / \mathrm{MPa}$ \\
\hline ICIE16 & $3.1 / 12.5 / 35.0$ & $69.77 / 0.51 / 28.41 / 1.30$ & $690{ }^{\circ} \mathrm{C} 1.5 \mathrm{~h}$ & $107.9 \pm 8.6$ & $74.9 \pm 1.3$ & $3.4 \pm 0.3$ \\
\hline $13-93$ & $3.3 / 15.8 / 39.5$ & $67.68 / 0.50 / 30.88 / 0.95$ & $700{ }^{\circ} \mathrm{C} 1 \mathrm{~h}$ & $132.4 \pm 9.3$ & $75.4 \pm 2.1$ & $15.3 \pm 1.8$ \\
\hline PSrBG & $3.3 / 10.8 / 30.5$ & $65.53 / 0.48 / 32.76 / 1.22$ & $690{ }^{\circ} \mathrm{C} 5 \mathrm{~h}$ & $124.8 \pm 12.4$ & $76.7 \pm 0.9$ & $8.4 \pm 0.8$ \\
\hline
\end{tabular}

"Where D10/D50/D90 is the particle size used, the modal interconnect diameter $\mathrm{D}_{\text {mode, }}$ \% defines scaffold porosity. 
(a)

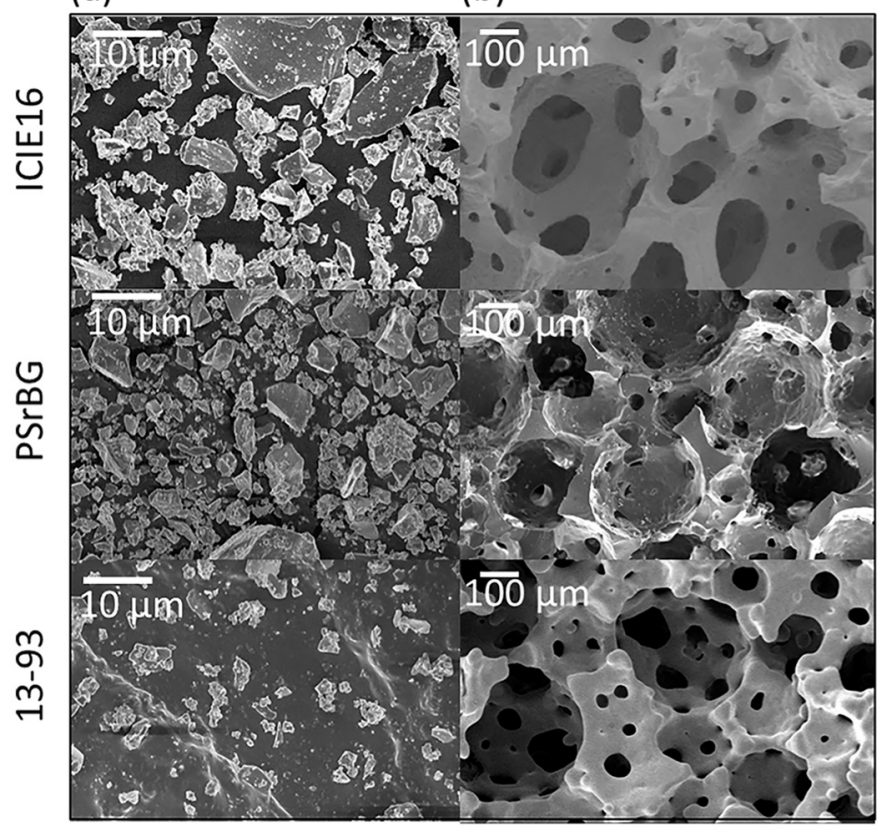

(c)
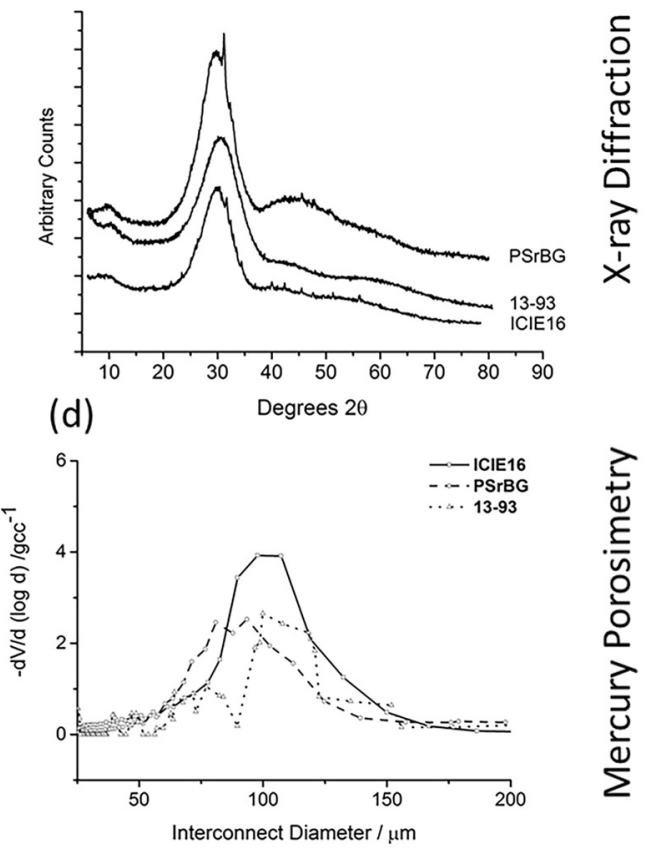

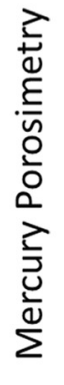

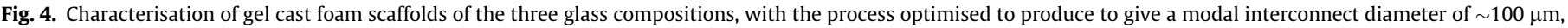

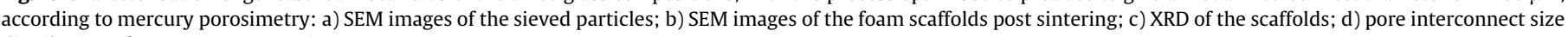
distributions from mercury porosimetry.

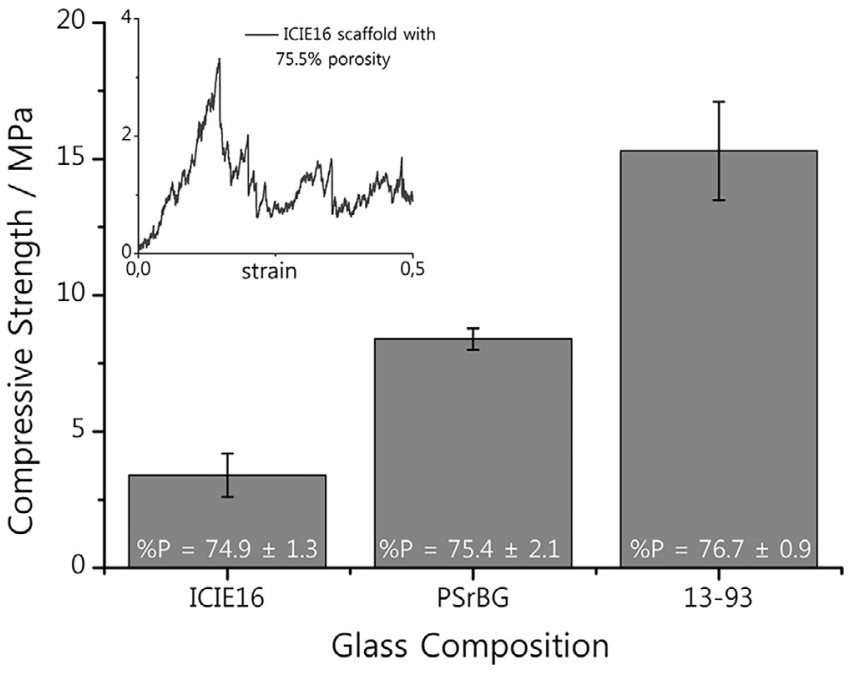

Fig. 5. Compressive strength of ICIE16, PSrBG and 13-93 with similar porosity (\%P). Inset: typical stress-strain results for scaffolds made of ICIE16.

A sintering temperature of $690^{\circ} \mathrm{C}$ with a $1.5 \mathrm{~h}$ dwell was therefore the optimum profile to gain enough flow to form continuous struts, while avoiding crystallisation, keeping the amorphous bioactive structure.

Once the process was optimised for ICIE16, the sintering variables were optimised for the other compositions. The aim was to produce scaffolds of each glass composition with interconnect sizes between 100-125 $\mu \mathrm{m}$. The composition of the glass did also affect the gel cast foaming process and the process of optimisation is summarised in Table 3 and Fig. 4.

Fig. 4 shows SEM images that demonstrate the formation of the scaffolds featuring open pore networks with complete sintering of the particles. In order to achieve this, the PSrBG had to be sintered for $5 \mathrm{~h}$ and $13-93$ for $1 \mathrm{~h}$ at $700^{\circ} \mathrm{C}$, due to both having higher $\mathrm{T}_{\mathrm{g}}$ compared to ICIE16 [5,27]. Fig. 4c shows that ICIE16 and 13-93 scaffolds were amorphous post sintering according to XRD. The XRD pattern for PSrBG showed a small unidentified peak but lowering the sintering temperature or dwell time to avoid this left the particles unsintered.

Compressive strengths varied between glass compositions (Fig. 5 and Table 3), even though the percentage porosity was similar. 13-93 had the highest compressive strength $(15.3 \pm 1.8 \mathrm{MPa})$ compared to PSrBG $(8.4 \pm 0.8 \mathrm{MPa})$ and ICIE16 (3.4 $\pm 0.3 \mathrm{MPa})$. Typical stress-strain results are shown in the inset for ICIE16 in Fig. 5. The higher strength of 13-93 was expected due to its higher network connectivity, and enhanced thermal processing.

13-93 was used as a bench mark against other scaffolds within literature. Work by Fu et al. produced scaffolds with similar morphology with porosities of $85 \pm 2 \%$ and compressive strengths of $11 \pm 1 \mathrm{MPa}$ for cylindrical scaffolds of $12 \mathrm{~mm}$ length and $6 \mathrm{~mm}$ in diameter [13]. The scaffolds produced by gel cast foaming gave slightly higher compressive strengths when tested.

\subsection{Dissolution and apatite layer formation}

Scaffolds of the three compositions and equivalent porosity and similar $\mathrm{D}_{\text {mode }}$ values were compared in SBF (Fig. 6). The $\mathrm{pH}$ of the SBF control was stable at around 7.4 throughout the time-period of the study, whereas the $\mathrm{pH}$ of the solution containing the glass scaffolds increased due to exchange of cations from the glass with $\mathrm{H}^{+}$from the SBF. ICIE16 caused the highest $\mathrm{pH}$ increase, peaking at 8.1 after $500 \mathrm{~h}$ of immersion, due to its lower network connectivity compared to PSrBG and 13-93, for which pH increased to 7.73 and 7.75 respectively by $500 \mathrm{~h}$. This higher increase in $\mathrm{pH}$ was a result of a greater $\mathrm{Ca}^{2+}$ ion release $\left(287.2 \pm 8.1 \mu \mathrm{g} \mathrm{ml}^{-1} 500 \mathrm{~h}\right.$ compared to 204-109 $\mu \mathrm{g} \mathrm{ml}^{-1}$ for the other glasses) which exchanged with of $\mathrm{H}^{+}$from the SBF. 


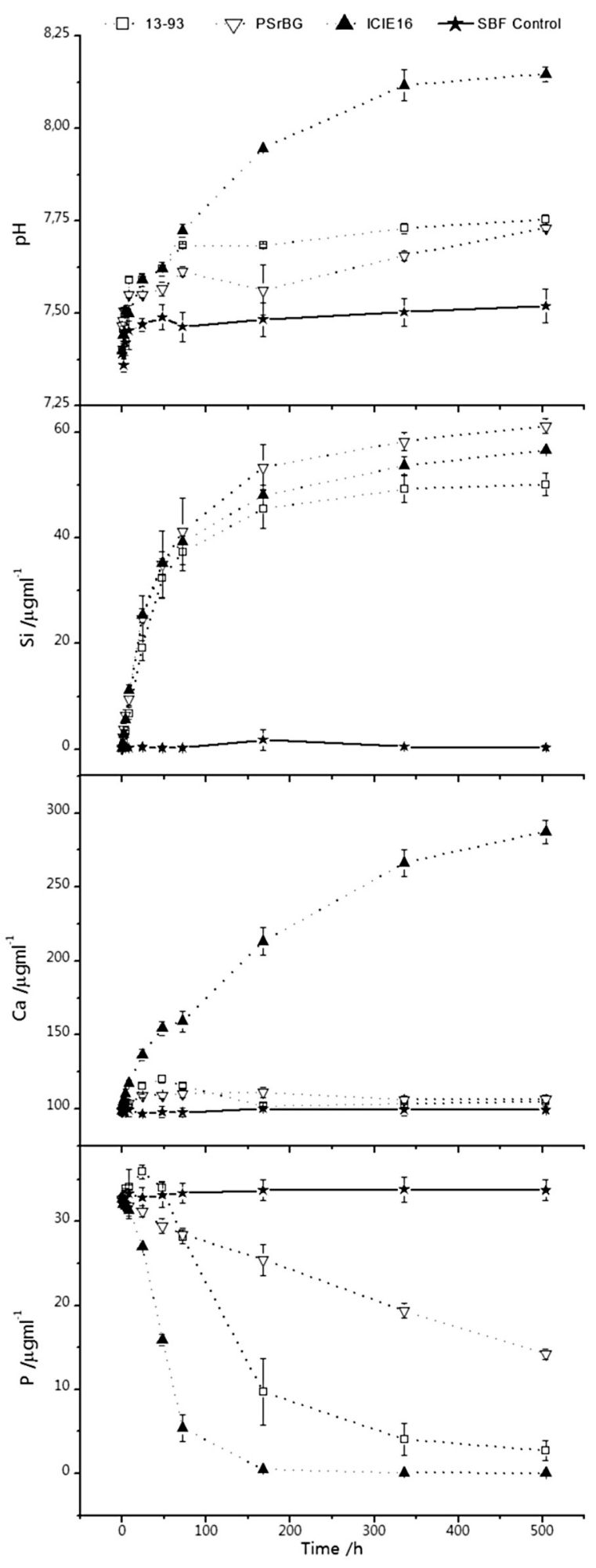

Fig. 6. Dissolution profiles in SBF following immersion of 13-93, PSrBG and ICIE16 scaffolds.

Soluble silica release over $72 \mathrm{~h}$ was similar for all 3 glasses regardless of their composition or network connectivity, with a steep release in the first 7 days followed by plateau at $48 \mu \mathrm{g} \mathrm{ml}^{-1}$ (13-93) and $58 \mu \mathrm{g} \mathrm{ml}^{-1}$ (ICIE16).
Phosphorus reduction from SBF is associated with the formation of a phosphate-rich (likely to be both calcium and phosphate rich) layer on the glass surface. Phosphorous reduction in SBF was more rapid for ICIE16, reducing to $0.5 \pm 0.2 \mu \mathrm{g} \mathrm{ml}^{-1}$ by $168 \mathrm{~h}$. Phosphorous levels in SBF containing PSrBG stayed stable at $31.87 \pm 0.4 \mu \mathrm{g} \mathrm{ml}^{-1}$ over the first $24 \mathrm{~h}$. After $24 \mathrm{~h}$, it reduced steadily to $14.2 \pm 0.6 \mu \mathrm{g} \mathrm{ml}^{-1}$ by the end of the study, indicating precipitation. Phosphorous content of the SBF containing 13-93 increased until $24 \mathrm{~h}$, showing release of phosphate from the glass, before it reduced to $2.73 \pm 1.2 \mu \mathrm{g} \mathrm{ml}^{-1}$ by the end of the study. Phosphate is likely to have been released from all scaffolds, but the phosphate content of ICIE16 and 13-93 was lower than PSrBG.

FTIR spectra of ICIE16 after SBF immersion showed a change at wavenumber 571 and $602 \mathrm{~cm}^{-1}$ by $72 \mathrm{~h}$ (Fig. 7A), corresponding to $\mathrm{P}-\mathrm{O}$ bending vibrations synonymous with orthophosphate formation, which is a component of HCA. XRD patterns show a change in the shape of the amorphous halo as immersion time in SBF increased, with a broad peak developing at $32^{\circ} 2 \theta$ which corresponds to (211) of HCA, and a secondary peak at $26^{\circ} 2 \theta$.

The P-O bending bands in the FTIR spectra of 13-93 scaffolds were not clearly defined at 571 and $602 \mathrm{~cm}^{-1}$ until 1 week of immersion, compared to $72 \mathrm{~h}$ for ICIE16. The XRD results showed a gradual shape change of the amorphous halo with time, as it did for ICIE16, but at a slower rate for 13-93.

PSrBG FTIR results did not show the twin bands associated with the P-O bending at 571 and $602 \mathrm{~cm}^{-1}$ but instead presented a broader band, often associated with amorphous calcium phosphate [28]. Slower HCA formation is likely to be due to the lower $\mathrm{pH}$ rise in the SBF (Fig. 6). The XRD of PSrBG showed a subtle change over the length of the study with HA peaks developing at $26^{\circ}, 32^{\circ}, 46^{\circ}$ and $49^{\circ} 2 \theta$. However, these were masked by a predominant peak at $31^{\circ} 2 \theta$, which formed during sintering.

When comparing the SEM images, by 3 weeks (Fig. 7c) all glass compositions had a continuous coating upon the surface. 13-93 had similar needle like formation as ICIE16, however their formation took longer than ICIE16. PSrBG SEM images showed a different morphology formed upon the surface compared with ICIE16 or 1393 , suggesting that the more complex composition affects HCA formation, retarding it compared to $13-93$, even though the NC' was much lower.

From the results, phosphorous reduction (measured by ICP) and calcium phosphate layer formation (measured by XRD and FTIR) was much faster in SBF containing ICIE16 than in SBF containing 13-93 or PSrBG. This could be for two reasons: there was much more calcium available from ICIE16's composition for dissolution and therefore for a calcium phosphorous rich precipitate to form; its network connectivity is also closest to that of 45S5, suggesting that glass dissolution and formation of HCA should be greater than that of the other two glasses.

XRD of PSrBG indicates the calcium phosphate was not crystalline orthophosphate and the morphology shown by SEM suggests that the precipitate is not the same as $13-93$ or ICIE16. This may be due to added strontium being available within the glass composition. Fredholm et al. [29] suggested that strontium substitution for calcium within a glass system results in greater bioactivity due to a weaker network structure as a result of the lower charge to size ratio of $\mathrm{Sr}^{2+}$ compared to $\mathrm{Ca}^{2+}$. Hoppe et al. [30] found that strontium substituted 13-93 nanoparticles showed an inverse relationship between strontium and bioactivity. Theoretical $a b$ initio calculations by Zeglinski et al. [31] indicated that $\mathrm{Sr}$ can substitute for $\mathrm{Ca}$ in both $\mathrm{Ca}-1$ and 2 sites within the HA lattice, which could support the proposal of a change in morphology of the precipitate seen at the surface when compared to 13-93 and ICIE16. 13-93 has the highest network connectivity, suggesting that it would be the least bioactive however, within this study its rate of formation of HCA and the relative drop in phosphorus and 
(a)

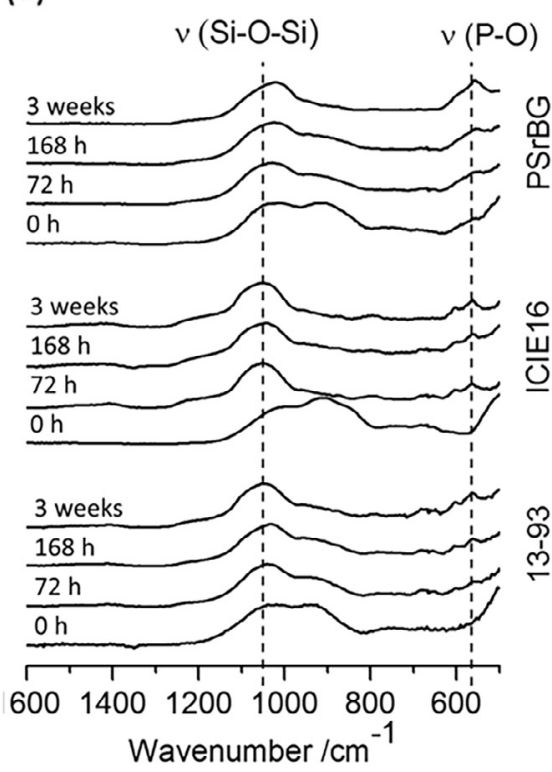

(b)

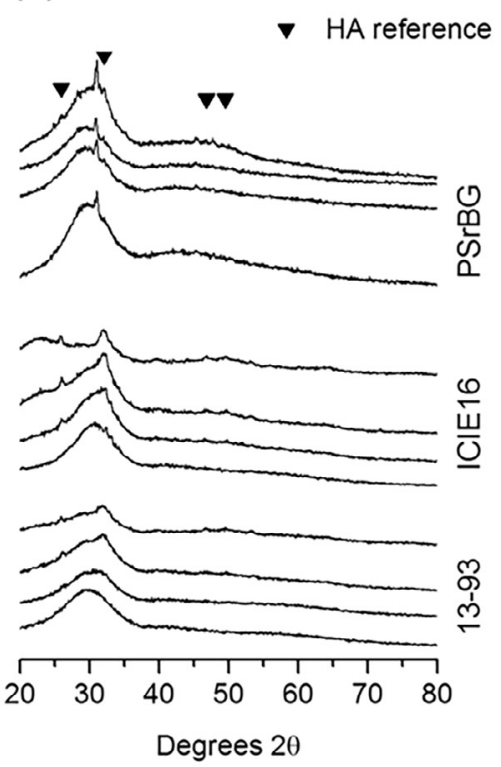

(c)

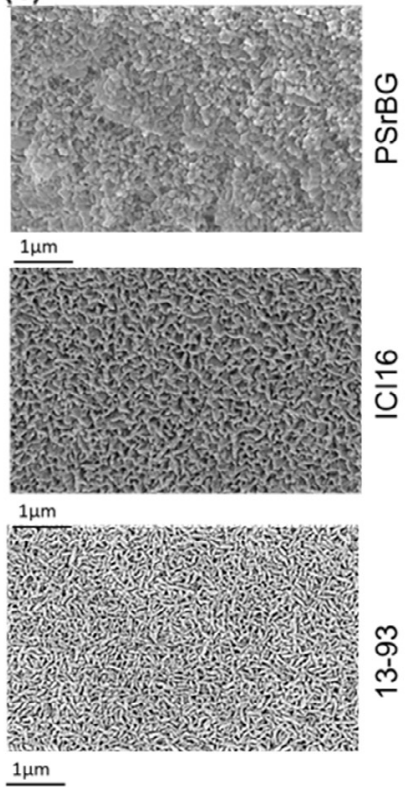

Fig. 7. Surface analysis of ICIE16, 13-93 and PSrBG scaffolds after immersion in SBF at 0 and 72 h, 168 h and 3 weeks a) XRD, b) FTIR, c) SEM images at 3 weeks.
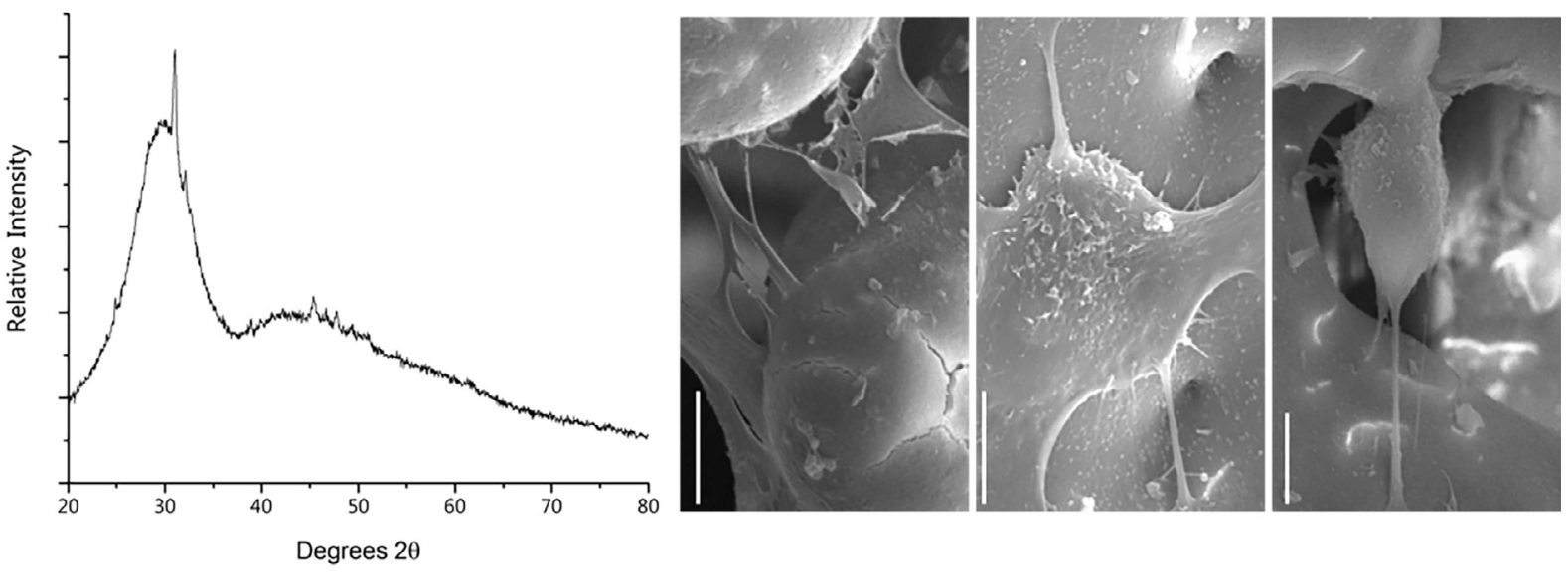

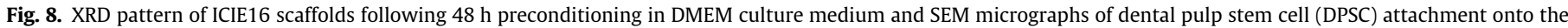
surface of the preconditioned scaffolds $24 \mathrm{~h}$ after seeding taken at different positions of the scaffold surface. Scale bar corresponds to $10 \mu \mathrm{m}$.

calcium in SBF was greater than that of PSrBG. These two glasses are difficult to compare as both of them have mixed alkali $[32,33]$ effects contributing to their glass dissolution, as well as different ratios of modifiers: formers: intermediates.

\subsection{Cell culture}

Following $48 \mathrm{~h}$ of preconditioning in DMEM, the scaffolds retained their amorphous nature with some evidence for HA formation (XRD pattern (Fig. 8) showed a principle peak at $32^{\circ} 2 \theta$ ). SEM images (Fig. 8) showed DPSC attachment and spreading on the scaffolds after $24 \mathrm{~h}$ of culture. Alamar blue and MTS assays indicated that cells were metabolically active and hence viable after 7 days of culture (Fig. 9a, b). The differences in the data obtained from the two assays can be explained by the fact that the assays test for intrinsic cell metabolism using different mechanisms. Alamar blue assay measures the reduction potential of the cells, and the MTS assay evaluates the activity of mitochondrial enzymes. Fig. 9c presents the ICP results of the media samples collected after each cell culture time-point (in addition to the preconditioning for $48 \mathrm{~h}$ ). Si was at its highest level $\left(73 \pm 0.4 \mu \mathrm{g} \mathrm{ml}^{-1}\right)$ and remained high after 3 and 5 days in culture. The effect of Si on osteoprogenitor cells is known to be dose-dependent [34], which could explain a small drop in cell activity compared to control for days 1-5. However differentiation was not investigated. At day 1 and day 3 , the calcium level was between $17-22 \mu \mathrm{g} \mathrm{ml}^{-1}$, being lower than the control (Fig. 9c) suggesting that the calcium may have been released from the glass initially and then combined with phosphate in the medium to form an amorphous or thin calcium phosphate layer on the scaffold surface (as it did in SBF, Fig. 6). After 5 days of culture, the calcium concentration increased from $17 \pm 4 \mu \mathrm{g} \mathrm{ml}^{-1}$ to $57 \pm 17.4 \mu \mathrm{g} \mathrm{ml}^{-1}$, almost twice the concentration of calcium in the control medium (DMEM) (Fig. 9c). The increase in cytosolic calcium affects a number of cellular functions. 

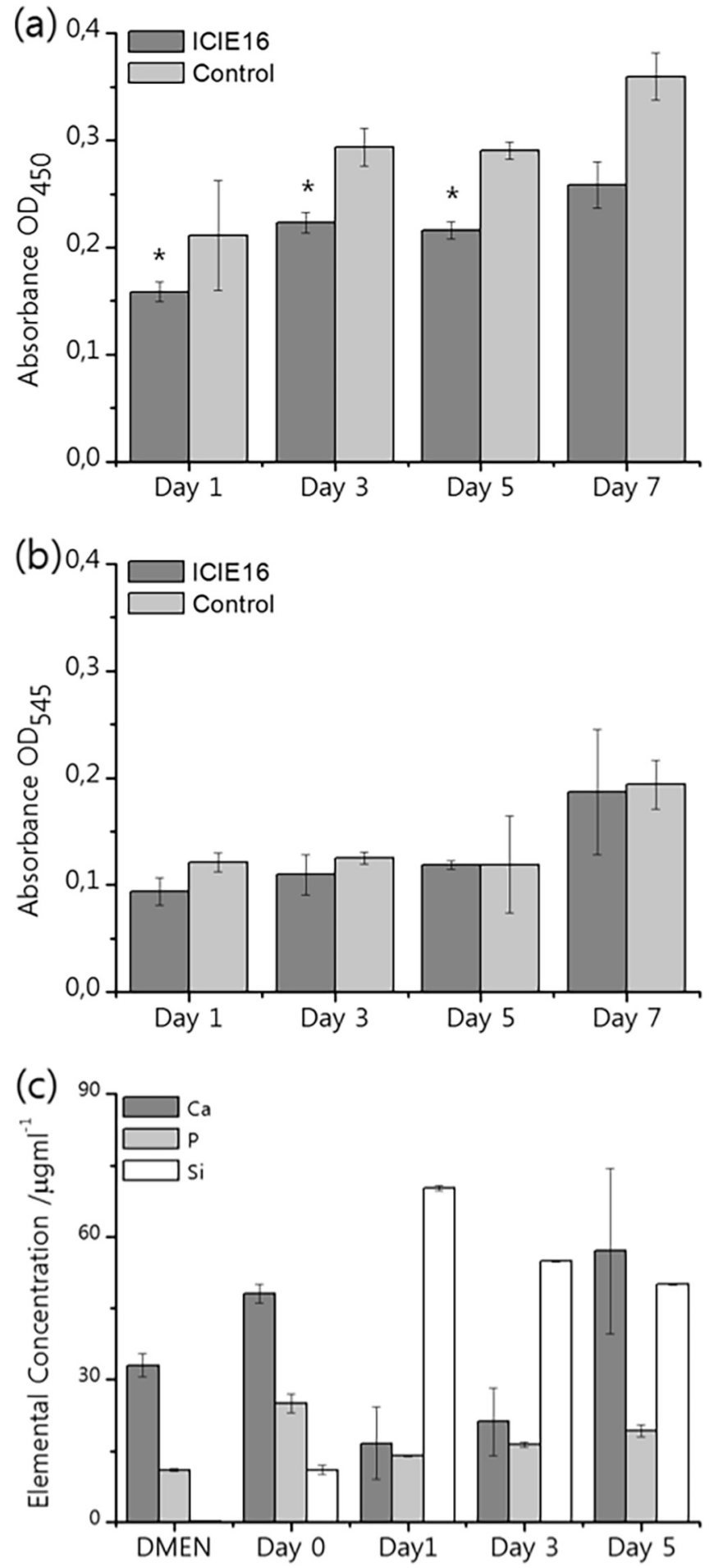

Fig. 9. Cell metabolic activity over time of dental pulp stem cells (DPSC) seeded on preconditioned (48 h) ICIE16 scaffolds (a) MTS; (b) Alamar blue assay; and (c) elemental concentration of cell culture media at each time point during cell culture study. Control was cells cultured on tissue culture plastic (TCP). Day 0 represents the culture media at the end of $48 \mathrm{~h}$ preconditioning of the scaffolds. Results represent the mean values and standard deviation (SD) of two individual experiments each performed in triplicate. $\left({ }^{*}\right)$ indicates the statistical significant difference $\left({ }^{*} \mathrm{p}<0.05\right.$ relative to control).

Calcium is an abundant cellular messenger, regulating numerous processes including apoptosis induction and also the function and activity of mitochondria. Recruitment of $\mathrm{Ca}^{2+}$ from extracellular environment can enter the mitochondria in various pathways, with unique channels handling transport of calcium to the inner membrane space resulting in changes in mitochondria activity [35]. If the intracellular level of calcium increases, hence changing cellular homeostasis, then this can have an adverse effect on cellular behaviour. But this phenomenon requires in-depth and thorough investigation.

\subsection{In vivo study}

$\mu \mathrm{CT}$ images from proof of principle in vivo studies (rabbit femoral condyle model) indicated that ingrowth from the preexisting surrounding femoral condyle occurred, resulting in bone regeneration, following implantation of ICIE16 and PSrBG gel-cast foam scaffolds at 7 and 12 weeks (Fig. 10). Fig. 10a and b show the location of the defect site, at time zero, and its relative size within the lateral femoral condyle. Fig. 10c and d show bone ingrowth at 7 weeks for PSrBG and Fig. 10e and $\mathrm{f}$ show the ingrowth for ICIE16. As the attenuation of the X-rays by the new tissue within the defects were similar to that by the host bone, we can assume the new tissue is new bone, but it will be confirmed by histology in future work. No cortical bone was evident at the defect site. The scaffolds were completely degraded. Fig. $10 \mathrm{~g}$ and h show the location of the defect site after 10 weeks, with no scaffold having been implanted. While there was some filling of the space, there appeared to be little bone growth and cortical bone did not form. At the 7 week time point, both scaffolds seem to have undergone total dissolution. The $\mu \mathrm{CT}$ imaging indicated that PSrBG stimulated more new bone growth than ICIE16, with new bone filling $10.3 \mathrm{~mm}^{3}$ of the original defect compared to $7.1 \mathrm{~mm}^{3}$ for ICIE16. By 12 weeks, the opposite was seen; the bone growth stimulated by the PSrBG was less than that of ICIE16 $\left(12.0 \mathrm{~mm}^{3}\right.$ compared to $14.4 \mathrm{~mm}^{3}$ for PSrBG and ICIE16 respectively). Cortical bone seemed to be present at the repaired defect at 12 weeks. The cortical bone around the defect that contained the ICIE16 was of thicker than it was for PSrBG (Fig. 10i-1). The trabeculated structure of the defect was similar to other regions of porous bone within the femoral head, supporting the hypothesis that bone remodelling was taking place (Fig. 10). More rapid regeneration was seen here compared the pioneering work by Oonishi et al., who implanted Bioglass particles (particle diameter $<1 \mathrm{~mm}$ ) in a similar defect, partly due to the Bioglass particles still remained in the defect at 12 weeks, due to their slower dissolution [36]. Here, the scaffolds seem to have completely degraded by 7 weeks, and were replaced by bone, which is likely to be because the scaffold morphology provides the appropriate morphology, increased surface area (e.g. $5.6 \mathrm{~m}^{2} \mathrm{~g}^{-1}$ compared to $0.15 \mathrm{~m}^{2} \mathrm{~g}^{-1}$ for $45 \mathrm{~S} 5$ particles [37] in a similar particle size range to those used by Oonishi [36]) and dissolution rate for bone remodelling. Ripamonti et al. [38] showed that concave pores could encourage more rapid osteogenesis and osteoclast remodelling of bioactive glasses has been observed in vitro [39]. Further experiments are required to verify this hypothesis, using histology and quantitative methods. Enhancement of early stage bone repair by PSrBG could be related to strontium release, which is known to have a positive effect on the formation and proliferation of osteoblasts, partially restoring trabecular volume [40]. We also hypothesise that the lower NC' of ICIE16, (2.13) enables greater and sustained glass dissolution and remodelling over the length of the study as compared to that of PSrBG (2.31), resulting in enhanced bone formation at 12 weeks. Bone ingrowth and regeneration was much improved over sol-gel derived scaffolds of similar architecture in rat tibia defects [32], which is likely to be due to more suitable rate of dissolution of cations from the melt-derived scaffolds, compared to the burst release of calcium ions within the pores of the sol-gel scaffolds. 

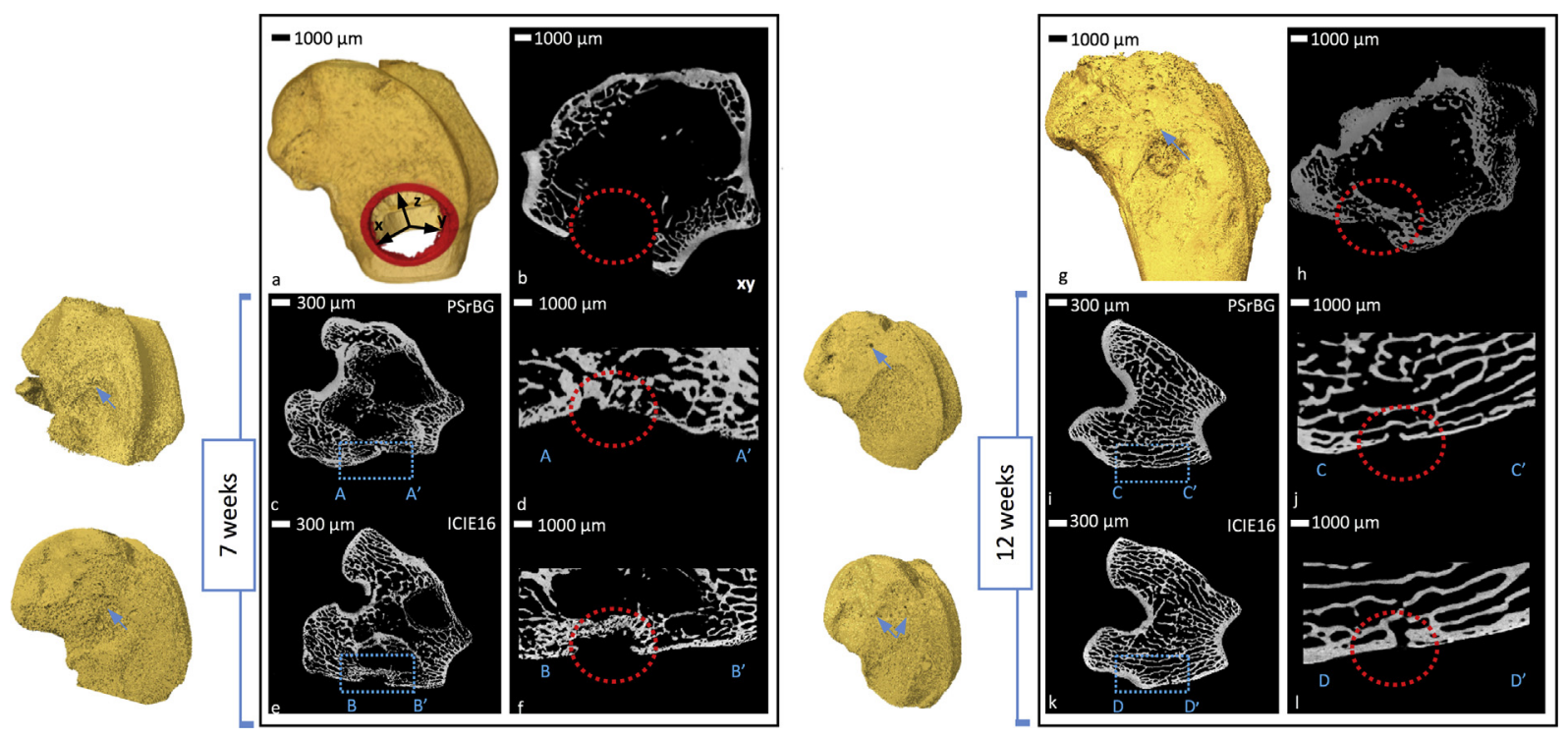

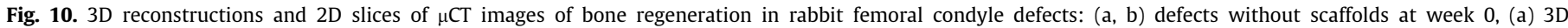

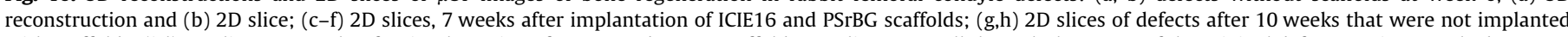

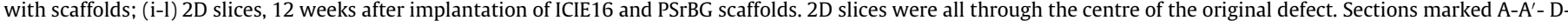

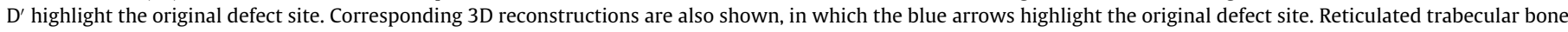

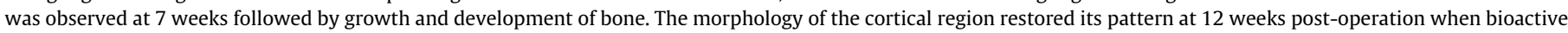
glass scaffolds were used. (For interpretation of the references to colour in this figure legend, the reader is referred to the web version of this article.)

\section{Conclusions}

By utilising the thermal gelation window of gelatin bioactive glass scaffolds can be produced via the adapted gel-casting method. Optimising surfactant concentration, while maintaining a gelatin: water: glass powder ratio of 1: 20:25, and sintering conditions amorphous glass foam structures can be formed with pore geometries and interconnects suitable for bone ingrowth. This technique has been adapted for use with three different silicate glasses, ICIE16, PSrBG and 13-93 all with different chemical compositions, and network connectivities. The optimised scaffolds had $\sim 75 \%$ porosity, and modal interconnect diameters between $100-$ $150 \mu \mathrm{m}$. Scaffolds of ICIE16, PSrBG, and 13-93 had compressive strengths of which fell within the range of cancellous bone of $3.4 \pm 0.3 \mathrm{MPa}, 8.4 \pm 0.8 \mathrm{MPa}$ and $15.3 \pm 1.8 \mathrm{MPa}$ respectively.

An in vivo pilot study comparing gel-cast foams of PSrBG and ICIE16 indicated that the foamed morphology supports and sustains bone growth across the 12 week time frame within in a femoral head defect in a rabbit model. Both scaffolds underwent complete biodegradation and ICIE16 seemed to encouraged more bone ingrowth than PSrBG after 12 weeks in situ, showing bone morphology similar to other regions of the femoral head, however further studies are required develop a deeper understanding of the potential of these scaffolds to support long-term bone regeneration in vivo.

\section{Acknowledgements}

This work was made possible by the facilities and support provided by the Research Complex at Harwell, funded in part by the EPSRC (EP/I02249X/1 and EP/I021566/1). Funding was also received from the EPSRC (EP/I020861/1) and Imperial College London. Alessandra Pinna is a Marie Sklodowska-Curie Individual Fellow. Raw data can be obtained from rdm-enquiries@imperial.ac.uk.

\section{References}

[1] J.R. Jones, Review of bioactive glass: from Hench to hybrids, Acta Biomater. 9 (2013) 4457-4486.
[2] I.D. Xynos, A.J. Edgar, L.D.K. Buttery, L.L. Hench, J.M. Polak, Ionic products of bioactive glass dissolution increase proliferation of human osteoblasts and induce insulin-like growth factor II mRNA expression and protein synthesis, Biochem. Biophys. Res. Commun. 276 (2000) 461-465.

[3] A. Hoppe, N.S. Gueldal, A.R. Boccaccini, A review of the biological response to ionic dissolution products from bioactive glasses and glass-ceramics, Biomaterials 32 (2011) 2757-2774.

[4] L.L. Hench, The story of Bioglass ${ }^{\circledR}$, J. Mater. Sci. - Mater. Med. 17 (2006) $967-$ 978.

[5] Z.Y. Wu, R.G. Hill, S. Yue, D. Nightingale, P.D. Lee, J.R. Jones, Melt-derived bioactive glass scaffolds produced by a gel-cast foaming technique, Acta Biomater. 7 (2011) 1807-1816.

[6] O.P. Filho, G.P. La Torre, L.L. Hench, Effect of crystallization on apatite-layer formation of bioactive glass 45S5, J. Biomed. Mater. Res. 30 (1996) 509-514.

[7] I. Elgayar, A.E. Aliev, A.R. Boccaccini, R.G. Hill, Structural analysis of bioactive glasses, J. Non-Cryst. Solids 351 (2005) 173-183.

[8] M.D. O'Donnell, R.G. Hill, Influence of strontium and the importance of glass chemistry and structure when designing bioactive glasses for bone regeneration, Acta Biomater. 6 (2010) 2382-2385.

[9] Q.Z. Chen, A.R. Boccaccini, Poly(D,L-lactic acid) coated 45 S5 Bioglass (R)-based scaffolds: processing and characterization, J. Biomed. Mater. Res., Part A 77A (2006) 445-457.

[10] A. Hoppe, B. Jokic, D. Janackovic, T. Fey, P. Greil, S. Romeis, J. Schmidt, W. Peukert, J. Lao, E. Jallot, A.R. Boccaccini, Cobalt-releasing 1393 bioactive glassderived scaffolds for bone tissue engineering applications, Am. Ceram. Soc. Appl. Mater. Interfaces 6 (2014) 2865-2877.

[11] F. Baino, M. Ferraris, O. Bretcanu, E. Verne, C. Vitale-Brovarone, Optimization of composition, structure and mechanical strength of bioactive 3-D glass-ceramic scaffolds for bone substitution, J. Biomater. Appl. 27 (2013) 872-890.

[12] Q. Fu, E. Saiz, A.P. Tomsia, Bioinspired strong and highly porous glass scaffolds Adv. Funct. Mater. 21 (2011) 1058-1063.

[13] Q. Fu, M.N. Rahaman, B.S. Bal, R.F. Brown, D.E. Day, Mechanical and in vitro performance of 13-93 bioactive glass scaffolds prepared by a polymer foam replication technique, Acta Biomater. 4 (2008) 1854-1864.

[14] Q. Fu, E. Saiz, A.P. Tomsia, Direct ink writing of highly porous and strong glass scaffolds for load-bearing bone defects repair and regeneration, Acta Biomater. 7 (2011) 3547-3554.

[15] R.G. Hill, D.S. Brauer, Predicting the bioactivity of glasses using the network connectivity or split network models, J. Non-Cryst. Solids 357 (2011) 38843887.

[16] S.J. Watts, R.G. Hill, M.D. O’Donnell, R.V. Law, Influence of magnesia on the structure and properties of bioactive glasses, J. Non-Cryst. Solids 356 (2010) 517-524.

[17] S. Brunauer, L.S. Deming, W.E. Deming, E. Teller, On a theory of the van der Waals adsorption of gases, J. Am. Chem. Soc. 62 (1940) 1723-1732.

[18] T. Kokubo, S. Ito, Z.T. Huang, T. Hayashi, S. Sakka, T. Kitsugi, T. Yamamuro, Ca, P-rich layer formed on high-strength bioactive glass-Ceramic A-W, J. Biomed. Mater. Res. 24 (1990) 331-343.

[19] A.L.B. Macon, T.B. Kim, E.M. Valliant, K. Goetschius, R.K. Brow, D.E. Day, A Hoppe, A.R. Boccaccini, I.Y. Kim, C. Ohtsuki, T. Kokubo, A. Osaka, M. Vallet-Regi, D. Arcos, L. Fraile, A.J. Salinas, A.V. Teixeira, Y. Vueva, R.M. Almeida, M. Miola, C. 
Vitale-Brovarone, E. Verne, W. Hoeland, J.R. Jones, A unified in vitro evaluation for apatite-forming ability of bioactive glasses and their variants, J. Mater. Sci. - Mater. Med. 26 (2015) 115.

[20] S. Gronthos, J. Brahim, W. Li, L.W. Fisher, N. Cherman, A. Boyde, P. DenBesten, P.G. Robey, S. Shi, Stem cell properties of human dental pulp stem cells, J. Dent. Res. 81 (2002) 531-535.

[21] H. Geng, N.M. Todd, A. Devlin-Mullin, G. Poologasundarampillai, T.B. Kim, K. Madi, S. Cartmell, C.A. Mitchell, J.R. Jones, P.D. Lee, A correlative imaging based methodology for accurate quantitative assessment of bone formation in additive manufactured implants, J. Mater. Sci. - Mater. Med. 27 (2016) 9.

[22] J.R. Jones, L.L. Hench, Regeneration of trabecular bone using porous ceramics, Curr. Opin. Solid State Mater. Sci. 7 (2003) 301-307.

[23] L.J. Vandeperre, A.M. De Wilde, J. Luyten, Gelatin gelcasting of ceramic components, J. Mater. Process. Technol. 135 (2003) 312-316.

[24] G. Novajra, P. Perdika, R. Pisano, M. Miola, A. Bari, J.R. Jones, R. Detsch, A.R. Boccaccini, C. Vitale-Brovarone, Structure optimisation and biological evaluation of bone scaffolds prepared by co-sintering of silicate and phosphate glasses, Adv. Appl. Ceram. 114 (2015) S48-S55.

[25] G. Novajra, P. Perdika, R. Pisano, F. Baino, J.R. Jones, A.R. Boccaccini, R. Detsch, C. Vitale-Brovarone, Tailoring of bone scaffold properties using silicate/ phosphate glass mixtures, Key Eng. Mater. 631 (2015) 283-288.

[26] S.F. Hulbert, S.J. Morrison, J.J. Klawitter, Tissue reaction to three ceramics of porous and non-porous structures, J. Biomed. Mater. Res. 6 (1972) 347-374.

[27] S. Fagerlund, J. Massera, M. Hupa, L. Hupa, T-T-T behaviour of bioactive glasses 1-98 and 13-93, J. Eur. Ceram. Soc. 32 (2012) 2731-2738.

[28] M.R. Filgueiras, G. La Torre, L.L. Hench, Solution effects on the surface reactions of a bioactive glass, J. Biomed. Mater. Res. 27 (1993) 445-453.

[29] Y.C. Fredholm, N. Karpukhina, R.V. Law, R.G. Hill, Strontium containing bioactive glasses: glass structure and physical properties, J. Non-Cryst. Solids 356 (2010) 2546-2551.

[30] A. Hoppe, B. Sarker, R. Detsch, N. Hild, D. Mohn, W.J. Stark, A.R. Boccaccini, In vitro reactivity of Sr-containing bioactive glass (type 1393) nanoparticles, J. Non-Cryst. Solids 387 (2014) 41-46.

[31] J. Zeglinski, M. Nolan, M. Bredol, A. Schatte, S.A.M. Tofail, Unravelling the specific site preference in doping of calcium hydroxyapatite with strontium from ab initio investigations and Rietveld analyses, Phys. Chem. Chem. Phys. 14 (2012) 3435-3443.

[32] D. Groh, F. Dohler, D.S. Brauer, Bioactive glasses with improved processing. Part 1. Thermal properties, ion release and apatite formation, Acta Biomater. 10 (2014) 4465-4473.

[33] M. Tylkowski, D.S. Brauer, Mixed alkali effects in Bioglass ${ }^{\circledR} 45 S 5$, J. Non-Cryst. Solids 376 (2013) 175-181.

[34] O. Tsigkou, J.R. Jones, J.M. Polak, M.M. Stevens, Differentiation of fetal osteoblasts and formation of mineralized bone nodules by 4555 Bioglass ( R) conditioned medium in the absence of osteogenic supplements, Biomaterials 30 (2009) 3542-3550.

[35] S. Patergnani, J.M. Suski, C. Agnoletto, A. Bononi, M. Bonora, E. De Marchi, C. Giorgi, S. Marchi, S. Missiroli, F. Poletti, A. Rimessi, J. Duszynski, M.R. Wieckowski, P. Pinton, Calcium signaling around mitochondria associated membranes (MAMs), Cell Commun. Signal 9 (2011) 10.

[36] H. Oonishi, L.L. Hench, J. Wilson, F. Sugihara, E. Tsuji, M. Matsuura, S. Kin, T. Yamamoto, S. Mizokawa, Quantitative comparison of bone growth behavior in granules of Bioglass (R), A-W glass-ceramic, and hydroxyapatite, J. Biomed. Mater. Res. 51 (2000) 37-46.

[37] P. Sepulveda, J.R. Jones, L.L. Hench, Characterization of melt-derived $45 S 5$ and sol-gel-derived 58S bioactive glasses, J. Biomed. Mater. Res. 58 (2001) 734740.

[38] U. Ripamonti, S. Ma, A.H. Reddi, The critical role of geometry of porous hydroxyapatite delivery system in induction of bone by osteogenin, a bone morphogenetic protein, Matrix 12 (1992) 202-212.

[39] S. Midha, W van den Bergh, T B. Kim, P.D. Lee, JR Jones, C A Mitchell, Bioactive glass foam scaffolds are remodelled by osteoclasts and support the formation of mineralized matrix and vascular networks in vitro, Adv. Healthcare Mater. 2 (2013) 490-499.

[40] P.J. Marie, M. Hott, D. Modrowski, C. De Pollak, J. Guillemain, P. Deloffre, Y. Tsouderos, An uncoupling agent containing strontium prevents bone loss by depressing bone resorption and maintaining bone formation in estrogendeficient rats, J. Bone Miner. Res. 20 (2005) 1065-1074. 